\title{
Eukaryotic translation initiation factors as promising targets in cancer therapy
}

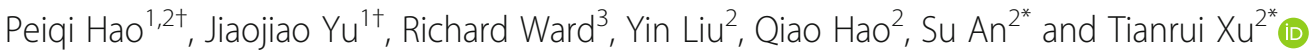

\begin{abstract}
The regulation of the translation of messenger RNA (mRNA) in eukaryotic cells is critical for gene expression, and occurs principally at the initiation phase which is mainly regulated by eukaryotic initiation factors (elFs). elFs are fundamental for the translation of mRNA and as such act as the primary targets of several signaling pathways to regulate gene expression. Mis-regulated mRNA expression is a common feature of tumorigenesis and the abnormal activity of elF complexes triggered by upstream signaling pathways is detected in many tumors, leading to the selective translation of mRNA encoding proteins involved in tumorigenesis, metastasis, or resistance to anti-cancer drugs, and making elFs a promising therapeutic target for various types of cancers. Here, we briefly outline our current understanding of the biology of elFs, mainly focusing on the effects of several signaling pathways upon their functions and discuss their contributions to the initiation and progression of tumor growth. An overview of the progress in developing agents targeting the components of translation machinery for cancer treatment is also provided.
\end{abstract}

Keywords: elF, mRNA translation, Cancer, MAPK, PI3K/Akt, mTOR

\section{Background}

The regulation of gene expression in eukaryotes can occur at different stages including gene transcription and mRNA translation. In comparison with transcriptional control, translational regulation of pre-existing mRNAs provides more direct, rapid and sensitive changes in intracellular levels of the encoded proteins and thus cellular adaptation during physiological and pathological conditions by rapidly reprogramming the proteome expression without the requirement for changes in RNA synthesis. Eukaryotic mRNA translation is a very complicated process that consists of four major phases:initiation, elongation, termination and ribosome recycling, while the regulation takes place mainly at the initiation stage which is the rate-limiting step of protein synthesis among the four steps of translation [1]. The major regulators in the initiation stage are the eukaryotic translation initiation factors (eIFs). In fact,

\footnotetext{
*Correspondence: aslxj@mail.ustc.edu.cn; tianruixu@kust.edu.cn

${ }^{\dagger}$ Peiqi Hao and Jiaojiao Yu contributed equally to this work.

${ }^{2}$ Faculty of Life Science and Technology, Kunming University of Science and Technology, Kunming 650500, China

Full list of author information is available at the end of the article
}

eukaryotes utilize many more initiation factors than do prokaryotes, reflecting the greater biological complexity of eukaryotic translation. First, in eukaryotes, the 43S ribosomal pre-initiation complex (PIC) which is composed of the 40S ribosomal subunit, the eIF2-GTP-initiating methionyl tRNA (Met-tRNAi) ternary complex and many other eIFs including eIF1, eIF1A, eIF3 and eIF5, is recruited to the 5' terminus of the mRNAs, and is thought to scan the 5', untranslated region (5'UTR), then the PIC moves towards the start codon, where the 60S ribosomal subunit joins the complex resulting the formation of the $80 \mathrm{~S}$ initiation complex. Then the $80 \mathrm{~S}$ complex is prepared to recruit the correct aminoacyl-tRNA into the A (aminoacyl) site, promoting synthesis of the first peptide bond and shifting initiation towards the elongation step [2].

During this process, eIFs can assist with the stabilization of the functional $80 \mathrm{~S}$ initiation complex at the start codon and also act as regulatory targets for translation initiation. Translation and translational regulation are recognized as a key node in inducing adaptive stress responses to conquer various stress conditions imposed on cancer cells 
by the tumor microenvironment, immunological surveillance, their continuous proliferation and cytotoxicity of antitumor drugs. It is well known that mis-regulation of many eIFs most frequently contributes to tumorigenic transformation, cancer development and progression, and is of the utmost interest when targeting cancer [2]. Studies in the past two decades have indicated that a group of initiation factors such as eIF4, eIF3, eIF2 and eIF5 are implicated in various types of cancer [3-6]. Additionally, eIFs have been shown to contribute to the hallmarks of cancer, including sustained proliferative signaling, uncontrolled growth, angiogenesis, invasion, metastasis, resistance to apoptosis and replicative immortality [7]. The expression level, availability and activity eIFs, which are usually regulated by several key signaling pathways, such as phosphatidylinositol 3-kinase (PI3K)/AKT, mitogen-activated protein kinase (MAPK), and mammalian target of rapamycin (mTOR) pathways, have significant effects on translation initiation. As such, mRNA translation is strictly regulated by signal pathways which can sense and respond to both environmental and intracellular stimuli. In this review, we describe our current knowledge about the basic functions of eIFs in translation initiation, in particular, discussing the crucial roles of eIF mis-regulation and the multiple regulatory pathways of eIF functions in tumorigenesis and tumor progression. The prognostic value of eIF perturbation in cancers and the possibility of eIFs serving as potential targets for the treatment of cancers are also explored.

\section{Overview the role of elFs in translation initiation}

Translation initiation in eukaryotes is, as described previously, the most highly regulated phase in the translation of most mRNAs, leading to the assembly of an elongationcompetent $80 \mathrm{~S}$ ribosome through the join of the large (60S) ribosomal subunits to the small (40S) ribosomal subunits with the Met-tRNAi positioned around the start codon (Fig. 1). Initiation begins with the formation of the eIF2-GTP-Met-tRNAi ternary complex, which then assembles with the $40 \mathrm{~S}$ ribosomal subunit, eIF1, eIF1A, eIF3 and probably eIF5 to form a 43S PIC [2] (Fig. 1).

Then the PIC is recruited to the 5' end of mRNA, labeled with by an inverted m7GpppN cap [8]. Prior to the attachment of PIC to this mRNA region, mRNA needs to be unwound or activated by the eIF4F complex consisting of the cap-binding protein (eIF4E), RNA helicase (eIF4A) and eIF4G with the assistance of eIF4B, eIF3 and PABP. The association of regulating factor eIF4B with eIF4A significantly enhances its helicase activity [2]. Once attached to the mRNA, the 43S PIC is considered to scan on the 5'untranslated region (5'UTR) in the $5^{\prime}$ to 3 ' direction until the start codon is recognized and the $48 \mathrm{~S}$ initiation complex formed. Once PIC recognizes the start codon, eIF1 is released, permitting the hydrolysis of eIF2-bound GTP and Pi release mediated by eIF5 [9] (Fig. 1).

These processes prompt the transition of PIC from an 'open' conformation to a 'closed' conformation, the latter stabilizing the interaction of PIC with mRNA. Then eIF5B-GTP collaborates with the eIF1A to assist in the formation of $80 \mathrm{~S}$ ribosomal initiation complex through the recruitment of the $60 \mathrm{~S}$ subunit to the $48 \mathrm{~S}$ initiation complex, a process which is accompanied by the release of eIF1, eIF2-GDP, eIF3, eIF4B, eIF4F and eIF5. Subsequent hydrolysis of GTP by eIF5B and the displacement of eIF5B-GDP and eIF1A from assembled 80S ribosome make the complex ready to enter the elongation phase of protein synthesis [2] (Fig. 1).

Signaling pathways promoting tumorigenesis possess growth factor signaling characteristics which strongly stimulate the activation of receptor tyrosine kinases (RTKs), MAPK and PI3K/AKT signaling pathways [2]. These pathways play a significant role in the regulation of eIF functions, indeed their mis-regulation usually causes aberrant translation, finally leading to tumorigenesis. To date, the roles of MAPK and PI3K/AKT signaling pathways in the regulation of eIFs are the bestcharacterized regulatory mechanism. Interestingly, both MAPK and PI3K/AKT pathways employ the mammalian target of rapamycin (mTOR) to regulate the functions of eIFs. Therefore, mTOR plays a leading role in the regulation of eIF functions and protein synthesis, and is recognized as the master regulator of protein synthesis and cell proliferation [10].

\section{mTOR}

mTOR is a conserved Ser/Thr kinase that orchestrates a broad spectrum of environmental and intracellular stimuli including growth factors, hormones and metabolic alterations to adjust growth and proliferation [11]. In mammals, mTOR is found to have two structurally and functionally distinct multiprotein complexes, named mTOR complex 1 (mTORC1) and mTOR complex 2 (mTORC2). mTORC1 is defined by its three core components: mTOR, Raptor (regulatory protein activated with mTOR) and mLST8 (mammalian lethal with Sec13 protein 8 , also known as the GTPase $\beta$-subunit like protein, GßL) [12] (Fig. 2).

Raptor, a specific component of mTORC1, endows the substrate specificity of mTORC1, in part by assisting in substrate recruitment to $\mathrm{mTORC} 1$ through interacting with several mTORC1 substrates [12, 13]. Whereas mLST8 interacts with the catalytic kinase domain of mTORC1, and may promote the stabilization of kinase activation loop, though mLST8 gene knockout studies indicated that it is unnecessary for the fundamental functions of mTORC1 [14]. 


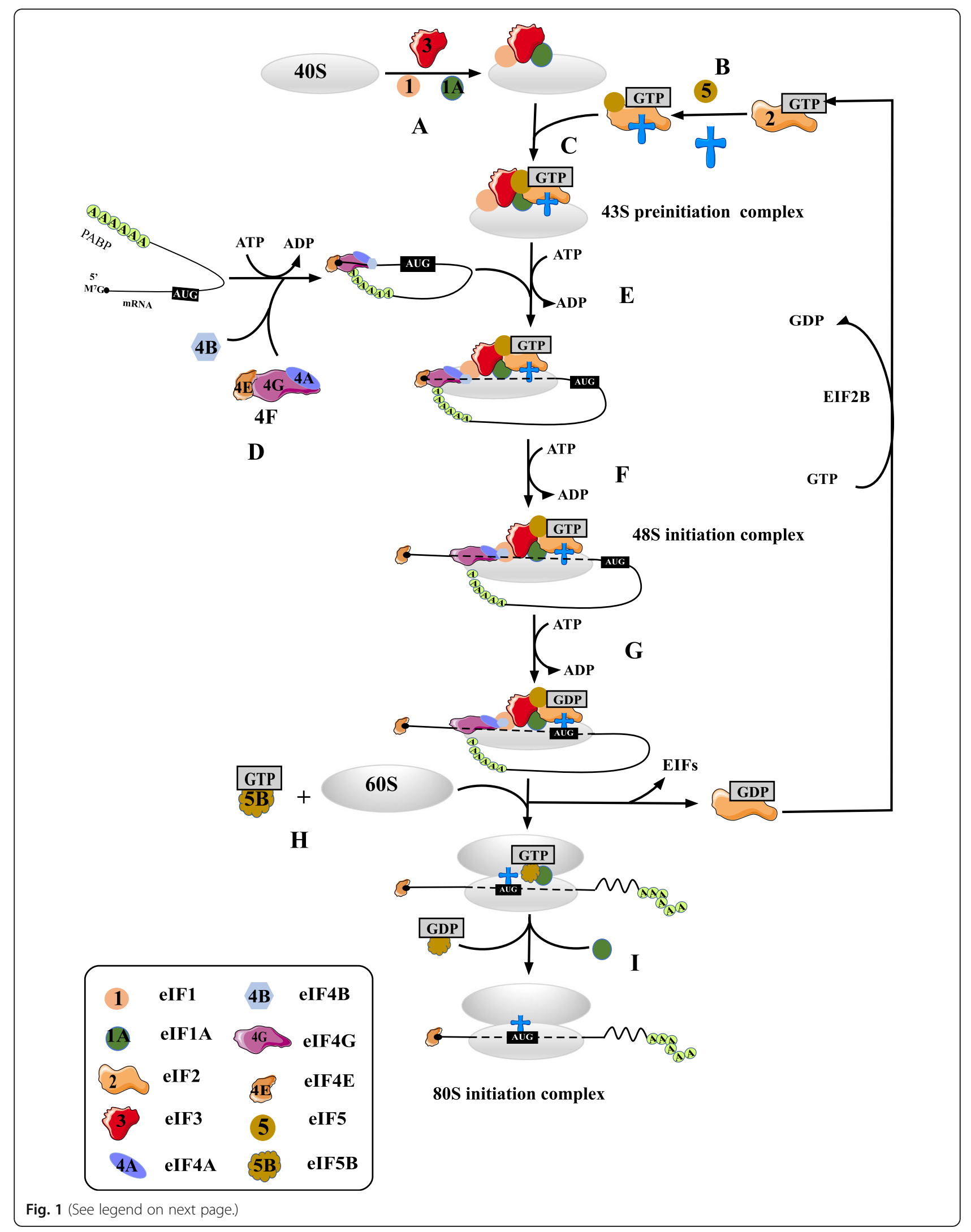


(See figure on previous page.)

Fig. 1 Schematic representation of the pathway of eukaryotic translation initiation. The whole process of eukaryotic translation initiation can be divided into nine stages: $\mathbf{a}$ the recycling of separated ribosomal subunits and elFs which are generated from the previous mRNA translations. $\mathbf{b}$ the formation of elF2-GTP-Met-tRNAi ${ }^{\text {Met }}$ ternary complex. $\mathbf{c}$ the formation of 43S PIC which is composed of elF2-GTP-Met-tRNAi ${ }^{\text {Met }}$ ternary complex, $40 \mathrm{~S}$ ribosomal subunits, elF1, elF1A, elF3 and elF5. $\mathbf{d}$ the activation of mRNA by elF4F complex with the assistance of elF4B, elF3 and PABP. e the attachment of $43 \mathrm{~S}$ PIC to mRNA. $\mathbf{f}$ the scanning of mRNA $5^{\prime} \mathrm{UTR}$ in a $5^{\prime}-3^{\prime}$ direction by $43 \mathrm{~S}$ PIC. $\mathbf{g}$ the recognition of start codon and the formation of $48 \mathrm{~S}$ initiation complex. $\mathbf{h}$ the jointing of $60 \mathrm{~S}$ ribosomal subunits to the $48 \mathrm{~S}$ complex with the assistance of elF5B-GTP and elF1A, and the concomitant displacement of elF2-GDP and other factors including elF1, elF3, elF4B, elF4F and elF5. i hydrolysis of elF5B-bound GTP and release of elF1A and elF5B-GDP from the 80 S ribosome, mRNA translation enters the elongation stage

In addition, mTORC1 also includes the other four associated proteins, PRAS40, Deptor (DEP domaincontaining mTOR-interacting protein), Rags A/B/C/D and Rheb. Two of the subunits, PRAS40 and Deptor [15], are negative regulators of mTORC1. PRAS40 has a functional TOR signaling (TOS) motif that associates with Raptor and thus may interfere with the binding of other mTORC1 targets to Raptor [16]. After phosphorylation by AKT or mTORC1, PRAS40 will dissociate from mTORC1 thus removing its inhibitory effects [17]. Rag GTPases, which belong to the Ras superfamily GTPbinding proteins, recruit mTORC1 to the lysosomal surface facilitating mTORC1 activation by Rheb [18]. Like mTORC1, mTORC2 also contains mTOR, mLST8 and

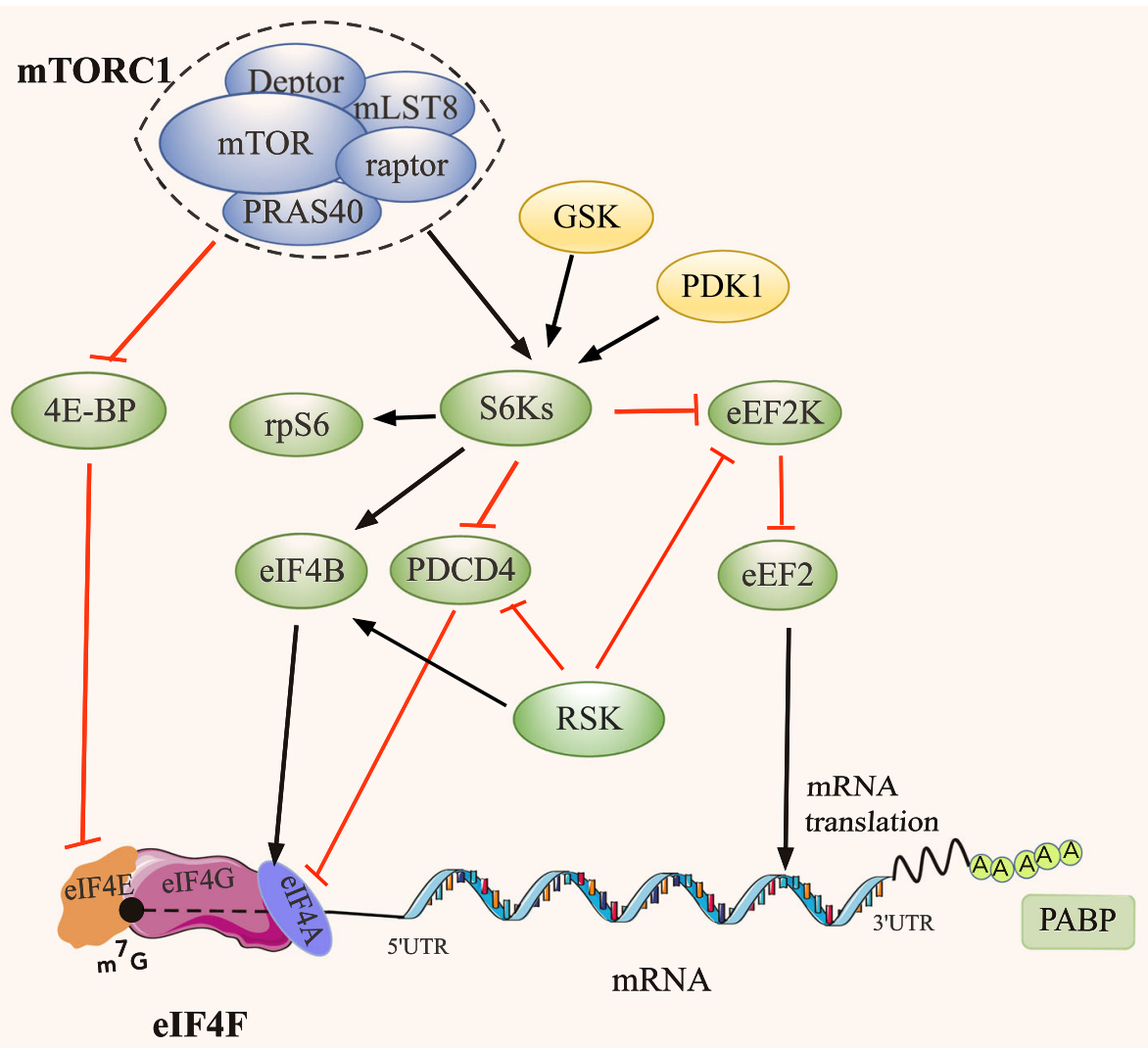

Fig. 2 The major substrates of mTORC1 and their signaling to the translational machinery. 4E-BPs and S6Ks are the two major mediators of the effects of mTORC1 on mRNA translation. In non-phosphorylated states, 4E-BPs block the assembly of the elF4F complex by competing with elF4G for binding to elF4E. When phosphorylated by mTORC1, the hyper-phosphorylation of 4E-BPs facilitates their dissociation from elF4E, allowing the interaction of elF4E and elF4G and the assembly of elF4F complex. In addition to 4E-BPs, S6Ks also mediate the effects of mTORC1 on mRNA translation. The major S6Ks substrates involved in the regulation of translation are rpS6, elF4B, eEF2K and PDCD4, which are also phosphorylated by other AGC kinases including RSK and AKT. rpS6 is a component of the $40 S$ ribosomal subunit, and elF4B is an auxiliary factor that enhances the RNA-unwinding activity of eEF4A. The phosphorylation of rpS6 and elF4B by AGC kinases significantly promote the translation of mRNA. PDCD4 is reported as pro-apoptotic factor and has been suggested to possess tumor suppressor properties. eEF2K functions as a negative regulator of protein synthesis via phosphorylation and inhibition of eEF2. The phosphorylation of PDCD4 and EEF2K by AGC kinases leads to PDCD4 degradation and the inhibition of eEF2K kinase activity, respectively. Black arrows and red T-bars represent stimulatory and inhibitory signals, respectively 
Deptor. Instead of Raptor, however, mTORC2 contains Rictor (rapamycin insensitive companion of mTOR), as well as the two regulatory subunits $\mathrm{mSin} 1$ and Protor $1 / 2$.

The different components and structures of mTORC1 and $\mathrm{mTORC} 2$ allow for distinct functions. For example, mTORC1 is relatively sensitive to rapamycin, while mTORC2 is relatively rapamycin resistant. In terms of protein synthesis, mTORC2 bind selectively to ribosomal membranes, where it can interact with its key substrates, the ACG kinases such as AKT, protein kinase C (PKC), and serum glucose kinase (SGK), and then promote their activity. In contrast, mTORC1 mainly associates with endosomal and lysosomal membranes, where it promotes the phosphorylation and activation of downstream substrates, 40S ribosomal protein S6 kinases (S6Ks) and 4E-binding protein 1 (4E-BP1). When considering their effects on eIFs functions, the one that is mainly involved in translational control and the regulation of eIFs functions is mTORC1, S6Ks and 4E-BP1 are the most extensively characterized and best-understood downstream substrates of mTORC1 [19].

\section{The functions of elFs regulated by mTORC1}

mTORC1 plays a critical role in stimulating global protein synthesis via regulating the translation of proliferation related, survival and tumor promoting mRNAs, as well as the house-keeping mRNAs. The best-understood effectors of mTORC1 in translation are 4E-BPs and S6Ks [20-22] (Fig. 2).

\section{E-BPs}

Cap-dependent translation initiation start from the assembly of eIF4F complex on the 5'-mRNA cap structure which is indispensable for recruiting mRNAs to ribosomes [23]. The eIF4F complex is a heterotrimer consisting of eIF4E (a cap-binding subunit), eIF4G (a scaffold protein) and eIF4A (a RNA helicase). eIF4E serves as the capbinding component, eIF4A acts as an ATP-dependent RNA helicase which unwinds mRNA secondary structure [24]. eIF4G is a large scaffolding protein which act as molecular bridges between eIF4E and eIF4A, and also interacts with PABP and eIF 3[23, 24]. 4E-BPs including 4EBP-1, 4E-BP-2 and 4E-BP-3 in mammals are negative translational regulators [25]. In their non-phosphorylated states, 4E-BPs impede the eIF4F complex formation through competing with eIF4G for the same binding site on eIF4E [26].

Upon activation, mTORC1 stimulates the hierarchical phosphorylation of 4E-BPs, such as the phosphorylation of Thr37 and Thr46 in human 4E-BP1 which leads to the further phosphorylation of Ser65 and Thr70 [27, 28]. 4EBPs are also phosphorylated by cyclin B-CDK1 (Cyclin Dependent Kinase 1). The hyper-phosphorylation of 4EBPs facilitates their disaggregation from eIF4E, thus allowing the association between eIF4E and eIF4G, and the formation of the eIF4F complex. It has been reported that phosphorylated 4E-BP1 levels in breast, ovary and prostate tumors is closely related to malignant development and poor prognosis regardless of the difference of upstream oncogenic stimulations [29].

Although eIF4E is a general translation initiation factor essential for cap-dependent translation initiation in eukaryotes [25], it is well known that the changes of eIF4E expression level and activity affect the translation of a specific subset of eIF4E-sensitive mRNAs, but do not influence the global protein expression. It is thought that eIF4E-sensitive mRNAs which are characterized by the long, complex and highly structured 5'-UTR mainly encoding proliferation and tumor-promoting proteins such as $\mathrm{Bcl}-\mathrm{xL}, \mathrm{C}-\mathrm{myc}$, Cyclins and vascular endothelial growth factor (VEGF) [30]. As the least abundant and most ratelimiting eukaryotic translation initiation factor, eIF4E controls the level of eIF4F complex. Therefore, mTORC1 can enhance the translational activity of eIF4E and stimulate the translation of eIF4E-sensitive mRNAs through the phosphorylation and inactivation of 4E-BPs [30].

\section{S6Ks}

Besides 4E-BPs, S6Ks also play an important role in mediating the effects of mTOR on mRNA translation [31,32]. There are two variants of S6K in mammals, S6K1 (S6K $\alpha)$ and S6K2 (S6K $\beta)$ [33], and the two kinases encoded by two independent genes share a high degree of homology [34]. Additionally, both S6K1 and S6K2 exhibit two distinct isoforms (p70- and p85-S6K1, p54- and p56-S6K2), which are produced via alternative transcription start site selection. The more abundant S6K1 isoform is p70-S6K1 which is predominantly localized in cytoplasm, whereas p85-S6K1 and both S6K2s are mainly to be found in the nucleus [35]. It is noteworthy that S6K1/2 double knockout mice have small body size and suffer from perinatal lethality [36], whilst small-body size is noticed in S6K1deficient mice, but not in S6K2-deficient mice [36]. Similarly, a single S6K isoform knockout mouse embryo fibroblasts and myoblasts exhibit abnormality in size but not propagation [37]. Thus, it is suggested that S6K1/2 have overlapping as well as non-redundant functions.

It has been observed that $\mathrm{S} 6 \mathrm{~K} 1$ plays an important role in control of oncogenic processes in estrogen receptor (ER)-positive breast cancer cells. S6k1 directly phosphorylates and activates ER $\alpha$ and in addition S6K1 expression is regulated by estrogen [38]. However, in small cell lung cancer, it is S6K2 but not S6k1 found to be important for FGF-2 induced-chemoresistance [39]. The mechanisms for these phenomena are still unclear, however, the development of specific S6K1 or S6K2 inhibitors will be helpful in exploring the specific functions of these two S6K isoforms. 
It is reported that $\mathrm{p} 70-\mathrm{S} 6 \mathrm{~K} 1$ can be activated by mTORC1 and phosphoinositide-dependent kinase 1(PDK1) via the phosphorylation of Thr389 in the hydrophobic motif and Thr229 in the activation loop, respectively. Recent findings have shown that glycogen synthase kinase (GSK) also activates p70-S6K1 by phosphorylating Ser371 in the turn motif [40]. The major S6K substrates involved in translation regulation are ribosomal protein $\mathrm{S} 6$ ( $\mathrm{rpS6}$ ), eIF4B, eukaryotic elongation factor 2 (eEF2) kinase (eEF2K) and programmed cell death 4 protein (PDCD4) (Fig. 2).

rpS6, a key component of the small 40S ribosomal subunit, was known as the first identified substrate of S6K and five residues including Ser235, Ser236, Ser240, Ser244 and Ser247 in the C-terminus of rpS6 can be phosphorylated by S6Ks [36], the other two serine residues of rpS6, Ser235 and Ser236, can be phosphorylated by another 90kDa ribosomal S6 kinase (RSK) [41]. Experiments using mice with wild-type rpS6 substituted by a phosphorylation negative mutant displayed severe growth defects which were also observed in S6K1/2 deficient mice [42]. Thus, it was proposed that the hyper-phosphorylation of $\mathrm{rpS} 6$ by S6Ks is implicated in the regulation of cell growth. However, the expression of phosphorylation negative rpS6 mutant showed a moderate up-regulation of global protein synthesis, whereas knockout of S6Ks had only a slight effect on overall translation rates [36, 42]. Therefore, the molecular mechanism for the influence of S6Ks and rpS6 on translation remains unclear.

eIF4B and eIF4H are two accessory factors that enhance the RNA-unwinding activity of eIF4A by promoting its processivity and switching its directionality. eIF4B can be phosphorylated by several members of the AGC kinase family on Ser406 (S6K and RSK) and Ser422 (S6K, RSK and $\mathrm{AKT}$ ) in a context-dependent manner [43], following which activated eIF4B promotes the translation of mRNA and stimulates cell proliferation and survival.

Human eukaryotic elongation factor 2 (eEF2) kinase (eEF2K) functions as a negative regulatory factors of protein synthesis via phosphorylation and inhibition of eEF 2[44]. eEF2K is also a substrate of S6Ks, being phosphorylated and inactivated by S6Ks, as well as RSK and ERK1/2, resulting in increasing eEF2 function and elongation rates $[45,46]$. PDCD4 is reported to be a proapoptotic factor and has been proposed to possess tumor suppressing properties. It is thought that PDCD4 interferes with the binding of eIF4G to eIF4A and blocks eIF4G and eIF4A interaction, leading to the inhibition of eIF4A helicase activity and the following suppression of cap-dependent translation [47]. Upon stimulation by growth factors, PDCD4 can be promptly phosphorylated on Ser67 and Ser457 by S6Ks and AKT, resulting in its degradation by the E3-ubiquitin ligase $\beta$-TrCP [48].

Additionally, S6Ks play a key role in triggering a negative regulatory feedback loop that restrains the activation of insulin-PI3K/AKT-mTORC1 pathway through the phosphorylation and inactivation of insulin receptor substrate 1 (IRS1), a major substrate of insulin receptor tyrosine kinase and crucial component in insulin signaling [49]. The limited therapeutic efficacy of rapamycin and rapamycin-induced AKT activation or persistent inhibition of S6K1 has been proposed to be caused by the loss of this negative regulatory feedback loop (Fig. 3).

\section{Major signaling pathways involved in the regulation of $\mathrm{mTORC} 1$ and elFs}

Growth factors and hormones are efficient stimulators for cancer cell growth and proliferation through activating several signaling pathways to increase protein synthesis. The major receptors, signal pathways and targets involved in this process are receptor tyrosine kinases (RTKs) and G protein-coupled receptors (GPCRs), PI3K/AKT and MAPK signal pathways, and the mTORC1 and eIFs targets, respectively [30] (Fig. 3). The growth of cancer cells and associated protein synthesis consume a large number of amino acids and energy, in the form of ATP, which have significant influence on the activity of mTORC1 and eIFs functions via the mediation of Rag GTPase, LKB1AMPK (AMP-activated protein kinase), and Wnt-GSK3 $\beta$ (glycogen synthase kinase $3 \beta$ ) signal pathways [30].

\section{mTORC1 and elFs regulated by the PI3K/AKT pathway}

Growth factors, hormones including insulin and insulinlike growth factor (IGF), and other agonist ligands activate PI3K through binding and activating RTKs, then PI3K converts phosphatidylinositol $(3,4)$-bis-phosphate (PIP2) to phosphatidylinositol (3,4,5)-tris-phosphate (PIP3), which in turn contributes to the activation of phosphoinositide-dependent kinase-1 (PDK1) and AKT. PIP3 levels are reversed by PTEN, which is a tumor suppressor phosphatase and tensin homolog, negatively regulating the PI3K/AKT pathway [50]. Tuberous sclerosis complex (TSC), a well-known suppressor of mTOR activity, is comprised of TSC2 and the scaffolding protein TSC1 [51]. TSC2 functions as a GTPase activating protein (GAP) towards Rheb (Ras homologue enriched in brain) and converts Rheb from its active GTP-bound form to the inactive GDP-bound form [52] (Fig. 3). Rheb is a small GTPase that promotes the activation of mTORC1 in active GTP-bound Rheb form [53, 54]. Active AKT, ERK and RSK phosphorylate TSC2 at multiple residues including Ser939, Ser981 and Thr1462, which are thought to impede its GAP activity, thus resulting in elevated levels of GTP-bound Rheb and enhanced mTORC1 activation [51] (Fig. 3).

Additionally, PRAS40 is a binding partner and suppressor of mTORC1 activity, activated AKT directly phosphorylates PRAS40, leading to its dissociation from mTORC1 and preventing its suppression of mTORC1 


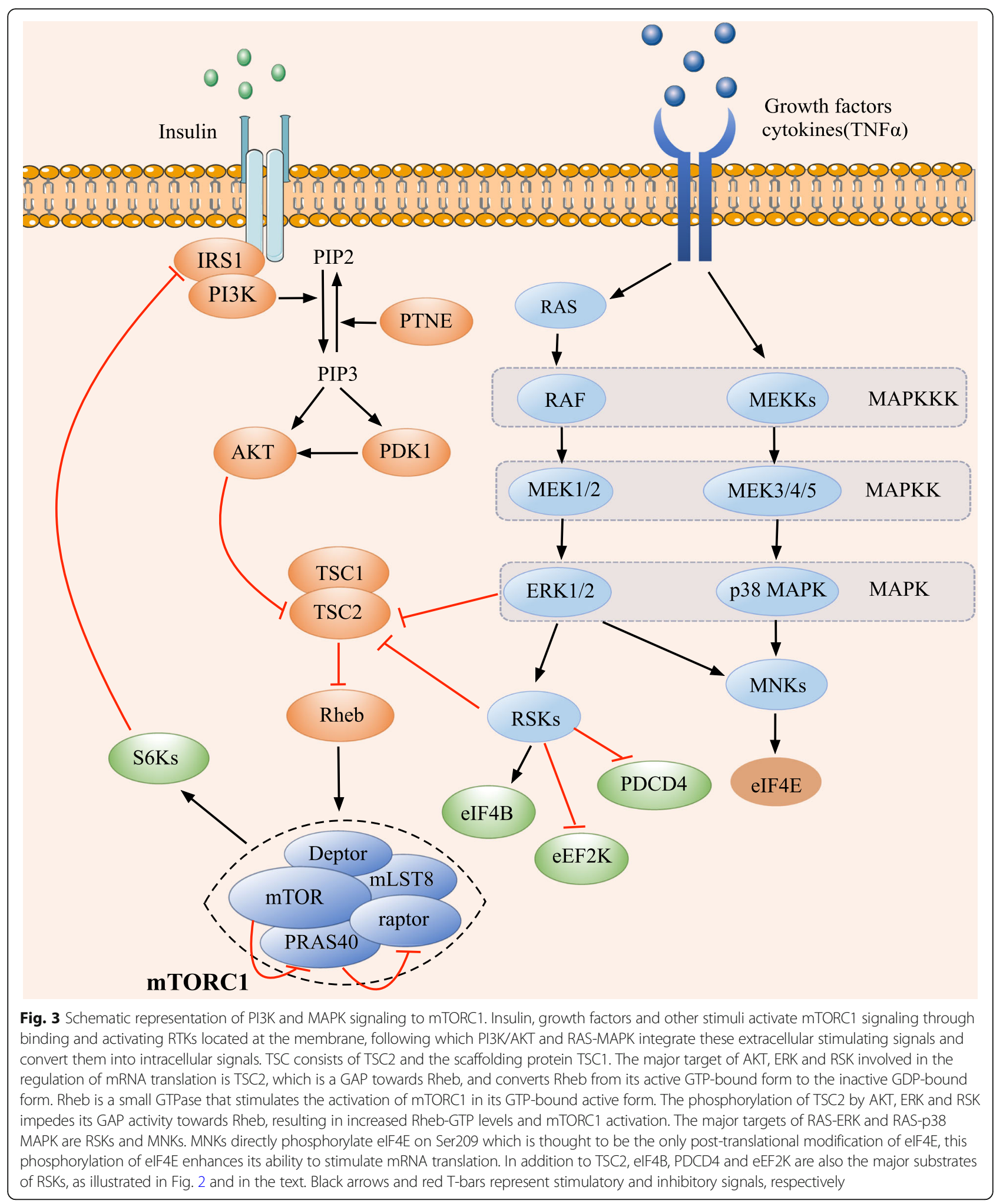

signaling to S6Ks and 4E-BP 1[17]. PRAS40 is also a direct target of mTORC1, the phosphorylation of PRAS40 by mTORC1 assists in the removal of its inhibitory effect on the downstream signaling of mTORC
1[55]. Thus, it is suggested that mTORC1-induced phosphorylation of PRAS40 is a positive regulatory feedback mechanism for PI3K/AKT-mTORC1 signal pathway (Fig. 3). 
Although it is well known that mTOR is often hyperactivated by mutations in its upstream signaling molecules, which include PI3K activating mutations and the loss-of-function mutations or gene copy deletion of the tumor suppressor PTEN [56, 57]. Direct evidence for mTORC1 functions involved in tumorigenesis comes from Tuberous Sclerosis, a multi-system genetic disease caused by defects or mutations of TSC1 or TSC2, consequently resulting in the hyper-activation of mTORC1, leading to widespread but benign tumor growth [58]. The lack of malignant transformation of Tuberous Sclerosis and the limited progression of these benign tumors may be due to mTORC1-S6K1-mediated negative feedback via phosphorylation of IRS-1 and inhibition of its activity, strongly down-regulating the signal transduction of most RTKs and PI3K/AKT pathways [59].

The significant role of PI3K in tumor development and progression makes it a promising therapeutic target $[60$, 61]. Great efforts have been made to develop PI3K inhibitors, some of which are currently undergoing clinical evaluation. Most agents targeting PI3K in the early phase clinical trials are ATP-competitive kinase inhibitors, including pan-PI3K inhibitors such as Buparlisib (BKM120) and dual PI3K/mTOR inhibitors such as BGT226. Currently, the most effective single agent PI3K pathway inhibitor is idelalisib (previously called CAL101 or GS1101) which has been approved by the FDA (U.S. Food and Drug Administration) for patients with chronic lymphocytic leukemia or non-Hodgkin lymphoma [62, 63].

\section{mTORC1 and elFs regulated by MAPK pathways}

The Ras-MAPK signal cascade is a critical pathway for cancer cell proliferation, migration and resistance to drug therapy. Driver mutations in Ras genes were the first specific genetic changes identified in human cancer and were found in up to $\sim 30 \%$ of all human tumors [64-66]. The Ras-MAPK signal pathway consists of three consecutive kinases: MAPK kinase kinase (MAP3K), MAPK kinase (MAP2K) and MAPK. MAP3K is typically activated by small GTPases such as Ras, following which MAP2K is phosphorylated and activated by activated MAP3K, and the activation of MAP2K in turn phosphorylates and activates MAPK, ultimately phosphorylating and activating transcription factors in the nucleus or translation factors and thus resulting in protein synthesis [65, 67]. This cascade is usually initiated by various stimuli from outside the cell. MAP3K is composed of three members, A-Raf, BRaf and C-Raf (Raf-1), whilst MAP2K is composed of MEK1 and MEK2, further downstream ERK/MAPK members are ERK1 and ERK2, which are the final effectors of MAPK pathway [67]. In mammals, MAPKs are grouped into four major families: the classical ERKs/MAPKs family, p38 MAPKs, C-Jun N-terminal kinases (JNKs) and Big MAPK-1 (BMK-1)/ERK5. Three of them, i.e., ERK, JNK and p38 have been widely studied and extensively characterized $[64,65]$.

The major MAPK pathways involved in the regulation of protein synthesis are Ras-ERK/MAPK and Ras-p38 MAPK pathways [68]. Both Ras-ERK/MAPK and Ras-p38 MAPK are stimulated and activated by a broad variety of stimuli such as growth factors, cytokines and a diverse set of environmental stresses. Although many factors activate both Ras-ERK/MAPK and Ras-p38 MAPK pathways, growth factors and stress stimuli typically activate the RasERK/MAPK and Ras-p38 MAPK signaling, respectively [69]. Many of substrates of ERK/MAPK and p38 MAPK have been demonstrated to control gene expression, the two major substrates, RSKs and MNKs (MAPK-interacting kinases), play a critical and direct role in the regulation of translation initiation [70, 71] (Fig. 3).

\section{RSKs}

The vertebrate RSKs (90 kDa ribosomal S6 kinase) family is composed of four highly similar isoforms, RSK1, RSK2, RSK3 and RSK4, which are 73 80\% identical. With the exception of RSK4, all RSKs have been demonstrated to be ubiquitously expressed in every developing and adult human tissues detected [72]. RSK1, RSK2 and RSK3 are usually present in the cytoplasm of quiescent cells, but are largely translocated to the nucleus upon outside stimulation and the activation of ERK1/2. The most striking feature of the RSK family is that its members have two non-overlapping and functional kinase domains, the $\mathrm{C}$ terminal kinase domain (CTKD) and the $\mathrm{N}$-terminal kinase domain (NTKD). The CTKD of RSKs contributes to the response to an upstream stimulating signals from ERK1/2, and then transmitting the activating signals to the NTKD with high efficiency and fidelity. It is the NTKD that phosphorylates the substrates of the RSKs [73]. The NTKD has the properties and functions of the AGC (protein kinase A, G and C) family kinases, explaining why RSKs, AKT and S6Ks have shared substrates [74].

The first evidence indicating that RSKs may take part in the regulation of mRNA translation came 30 years ago when it was recognized as an rpS6 kinase in Xenopus laevis oocytes. Subsequent studies demonstrated that activated RSKs associated with polysomes and enhanced the phosphorylation of several ribosome-associated proteins [75]. With the use of rapamycin, S6K1 and S6K2 were identified as the principal rpS6 kinases operating in somatic cells [76]. Studies using the cells from S6K1/2- deficient mice further verified these discoveries, but also indicated that there were low levels of rpS6 phosphorylation on Ser235 and Ser236, which was dependent on ERK1/2 activation [36]. The role of this specific regulation remains unclear, however, these results propose that RSK affords a mTOR-S6K independent but ERK1/2 dependent signal for regulating mRNA translation initiation. 
Ras-ERK/MAPK signaling influences the PI3K/mTOR pathway at diverse levels to control mRNA translation. Additionally, as mentioned above, RSK directly regulates and phosphorylates multiple components of the translation initiation apparatus including rpS6, eIF4B and eEF2K, which are also the substrates of S6Ks. As members belonging to AGC protein kinase family, RSK and S6K phosphorylate eIF4B on the same residue, resulting in its enhanced interaction with eIF3 and increased translation rates. However, the phosphorylation of eIF4B by RSK and S6K is in a growth factor dependent manner, and the two phosphorylation sites show different phosphorylation rates [43].

The phosphorylation of eEF2K and PDCD4 by RSK causes the inhibition of eEF2K kinase activity and PDCD4 degradation, respectively. eEF2K and PDCD4 are two major negative regulators in mRNA translation, thus, the elimination of their negative effects on translation through phosphorylation by RSK greatly promotes protein synthesis $[45,77]$. In addition, since GSK3 $\beta$ phosphorylates eIF2B and inhibits its functions in mRNA translation, RSK-mediated phosphorylation and inhibition of GSK3 $\beta$ promotes cancerous proliferation [78].

\section{MNKs}

MNKs have four molecular isoforms including MNK1a, MNK1b, MNK2a and MNK2b generated by alternative splice. MNK2a displays a higher basal kinase activity than other isoforms owing to its continuous association with ERK1/2 [79]. The interaction between the Nterminal regions of MNKs and the C-terminal domain of eIF4G recruits MNKs to eIF4E, finally resulting in the phosphorylation of eIF4E on Ser209, which is the only post-translational modification of eIF4E [80]. eIF4E phosphorylation was suggested to be an important event in tumorigenesis and tumor progression [81]. As far as transforming ability being considered, the nonphosphorylated eIF4E S209A mutant is less efficient than its wild-type counterpart, in vitro and in vivo [80]. Furthermore, constitutively activated MNK1 promotes tumor progression in a way similar to eIF4E, and the kinase-inactive MNK mutant suppresses the proliferation of cancer cells in vivo, thus, suggesting the critical role of MNK/eIF4E pathway in tumorigenesis [82].

\section{Regulation of mTORC1 by amino acids through Rag GTPase}

Currently, it is known that amino acids, particularly the branched chain amino acids, are indispensable nutrients for cancer cell proliferation and are used by cancers in various biosynthetic pathways and as a source of energy [83]. A significant step in deciphering mTORC1 activation by amino acids was made with the identification of the Rag GTPases as mediators of amino acid signaling to
mTORC1 [84-86]. In Saccharomyces cerevisiae, amino acids activate TORC1 through the Vam6/VPS39-Gtr1/ Gtr2 axis. Vam6/VPS39 functions as a GEF (guanine nucleotide-exchange factor) for the Gtr1 GTPase, which is a component of the vacuolar membrane-associated TORC1-Ego1/2/3 complex and causes TORC1 activation [84, 87]. In mammals, the Rag GTPases have four isoforms including Rag A, Rag B, Rag C and Rag D. Rag A and B, and Rag $\mathrm{C}$ and $\mathrm{D}$ are functionally overlapping proteins and share $90 \%$ and $80 \%$ sequence identity, respectively. Rag A binds to Rag C or Rag D, Rag B also binds to Rag C or Rag D to form a stable and active heterodimeric complex [88]. Under amino acids sufficient conditions, an active Rag complex is composed of GTP-binding Rag A or Rag B and GDP-binding Rag C or Rag D. The Rag GTPases are unable to directly promote kinase activity of mTORC1, but are able to recruit and anchor mTORC1 to the cytoplasmic surface of lysosomes and consequently enhancing mTORC1 activation by Rheb [86].

Ragulator functions as a GEF for Rag A/B and also as a scaffold to stabilize the Rag complex to the lysosome. $\mathrm{v}$-ATPase associates with Ragulator and is required for mTORC1 activity [89]. GATOR1 (GAP activity towards Rags 1) complex acts as a GAP for Rag A/B GTPase and inhibits mTORC1 activity [90]. The GATOR2 complex interacts with and inhibits GATOR1 (Fig. 4).

Different amino acids have their specific intracellular sensors and activate mTORC1 via distinct pathways. Sestrin $1 / 2$ and CASTOR1/2 (cellular arginine sensor for mTORC1 complex1/2) are cytosolic leucine and arginine sensor, respectively [91-93]. Both leucine and arginine disrupts the association of sestrin $1 / 2$ and CASTOR $1 / 2$ with GATOR2, resulting in the elimination of their inhibition towards GATOR2 [94, 95] (Fig. 4). FLCN and its binding partner FNIP2 were identified as Rag-interacting proteins with GAP activity for Rag C/D, but not for Rag A/B [96]. SLC38A9 was recently characterized as a lysosomal arginine sensor and amino acid transporter that directly associates with Ragulator [97]. By regulating the expression levels of SLC38A,it was found that SLC38A plays a key role in mTORC1 activation by amino acids, especially arginine [98] (Fig. 4).

\section{Regulation of mTORC1 by energy levels and oxygen availability}

Energy levels and oxygen availability fluctuate significantly during tumor progression and have great influence on cancer cell proliferation [99]. Alterations in cellular energy levels are detected by AMPK, which functions as the energy sensor for mTORC1 [100]. AMPK is a heterotrimeric complex that is composed of a catalytic subunit $\alpha$ and two regulatory subunits $\beta / \gamma$. AMPK can be stimulated and activated by various forms of intracellular stress, particularly the elevated cytosolic AMP/ATP or ADP/ATP ratios, 


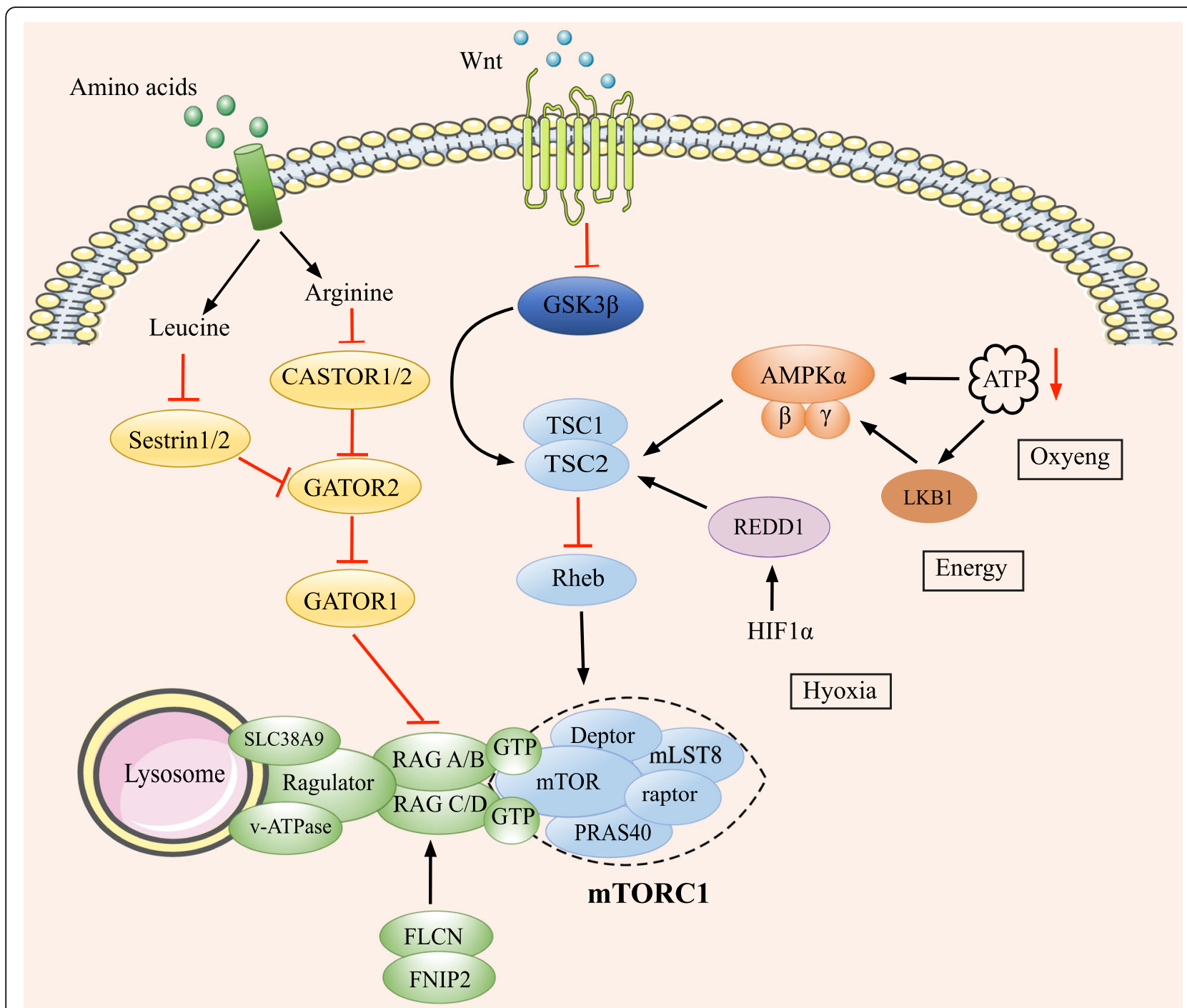

Fig. 4 Schematic representation of amino acid, energy and Wnt signaling to mTORC1. Rag GTPases were identified as mediators of amino acid signaling to mTORC1. When an adequate supply of amino acids is present, an active Rag complex consists of GTP-bound Rag A or Rag B and GDP-bound Rag C or Rag D. The Rag complex is able to recruit and anchor mTORC1 to the lysosomal surface which facilitates mTORC1 activation by Rheb. Ragulator functions as a GEF for Rag A/B and also as a scaffold to help anchor the Rag complex to the lysosome. V-ATPase interacts with Ragulator and is required for mTORC1 activity. The GATOR1 complex functions upstream of the Rag complex as a GAP for Rag A/B GTPase and inhibits mTORC1 activity. The GATOR2 complex interacts with and inhibits GATOR1. Sestrin $1 / 2$ and CASTOR1/2 are cytosolic leucine and arginine sensor, respectively. The presence of leucine and arginine disrupts the association of Sestrin $1 / 2$ and CASTOR1/2 with GATOR2, resulting in the elimination of their inhibition towards GATOR2. SLC38A9 is an important lysosomal arginine sensor and amino acid transporter that directly interacts with Ragulator. FLCN and its binding partner FNIP2 were identified as Rag-interacting proteins with GAP activity for Rag C/D, but not for Rag A/B. Reduction in oxygen or energy levels are sensed by AMPK which can be activated by upstream kinase LKB1 under the conditions of the increased intracellular AMP/ATP and ADP/ATP ratios. The activated AMPK phosphorylates TSC2 and enhances its GAP activity towards Rheb-GTP, finally resulting in the inhibition of mTORC1 activity. Hypoxic stress also stabilizes the transcription factor HIF1a which drives the expression of REDD1. The latter is a negative regulator of mTORC1 activity. Additionally, the activated Wnt signaling pathway stimulates mTORC1 activity via GSK3 3 repression. Black arrows and red T-bars represent stimulatory and inhibitory signals, respectively

because AMP or ADP binding to the regulatory AMPK $\gamma$ subunit promotes its phosphorylation and activation by upstream kinase LKB1 [101]. The phosphorylation of AMPK activates TSC2 and promotes its GAP activity towards Rheb-GTP, finally leading to the suppression of mTORC1 activity [102, 103] (Fig. 4).
The phosphorylation sites of TSC2 for AMPK are different from those for Akt, and TSC2 phosphorylation by Akt is suggested to suppress its GAP activity and promotes mTORC1 activation. Additionally, other studies indicate that activated AMPK can inhibit mTORC1 in a TSC2-independent manner. These studies reported that 
two well-conserved serine residues in the mTOR interacting partner Raptor can be directly phosphorylated by AMPK. The phosphorylation of Raptor subsequently recruits 14-3-3 to bind to Raptor and leads to the suppression of mTORC1 activity [104]. Therefore, Akt-TSC2mTORC1 and LKB1-AMPK or TSC2-mTORC1 play a critical role in balancing cell growth and energy supply.

Additionally, it is well known that the activation of the Wnt pathway inhibits GSK3 $\beta$, resulting in the enhanced stability of transcription factors such as $\beta$-catenin, and the transcription of a wide range of growth-promoting genes. Wnt signaling also has a great effect on mTORC1 activity. The Wnt signaling and mTORC1 pathways are linked by GSK3 $\beta$ which also phosphorylates TSC2, and these phosphorylation events require previous phosphorylation of TSC2 by AMPK. The sequential phosphorylation of TSC 2 by AMPK and GSK3 $\beta$ promotes the GAP activity of TSC2 towards Rheb-GTP, leading to the suppression of mTORC1. Therefore, the activated Wnt signaling pathway enhances the mTORC1 activity via GSK3 $\beta$ repression (Fig. 4).

In addition, oxygen availability also plays an important role in the activation of mTORC1. Reduction in oxygen limits ATP production, thereby resulting in the activation of LKB1 and AMPK, and the suppression of mTORC1. Hypoxic stress also stabilizes a transcription factor HIF1 $\alpha$ (hypoxia-inducible factor $1 \alpha$ ) which promotes the expression of a range of proteins such as REDD1 (regulated in development and DNA damage response) [105]. REDD1 impedes the activity of mTORC1 by competing with 14-33 for TSC2 binding to restrain the inhibitory binding of 14-3-3 to TSC2, finally resulting in the suppression of mTORC1 signaling [106] (Fig. 4).

\section{elFs mis-regulation in human cancer and potential targets for cancer therapy}

elF1 and elF1A mis-regulation in human cancer

eIF1 and eIF1A are essential for the formation of PIC which binds to 5'-Cap region and shifts to the translation initiation codon. eIF1 was identified as a genotoxic and endoplasmic reticulum stress-inducible protein [107]. The induced expression of eIF1 is detected in various human cancer cell lines treated with UV or base damaging agents (Table 1) [107]. The mutations of eIF1A within its unstructured $\mathrm{N}$-terminal tail are frequently observed in several types of malignancies. Recently, it was found that eIF1A differentially affects the translation of certain mRNAs. eIF1A knockdown causes a significant enrichment of cell cycle-related mRNAs, which are predominantly characterized by the long length of their 5'-UTR. Conversely, eIF1A knockout leads to an increased rate of 5'UTR translation initiation at a near cognate start codons, suggesting a predominant role of eIF1A in inhibiting 5'UTR translation. More importantly, cancer-associated mutants of the eIF1A N-terminal tail enhance the eIF1A functions towards a long 5'UTR and promote the expression of long 5'UTR-containing genes which control cell division cycle [108].

\section{elF2 mis-regulation in human cancer}

eIF2 is a heterotrimeric tRNA carrier composed of the components eIF2 $\alpha$, eIF2 $\beta$ and eIF2 $\gamma$, which together take part in the formation of the eIF2-Met-tRNAi-GTP heterotrimer complex. During translation initiation, eIF2 $\alpha$-GTP is hydrolyzed to yield eIF2 $\alpha$-GDP. eIF2B is a GEF which promotes the recycling of GTP bound to eIF $2 \alpha$, and this process is blocked by the phosphorylation of eIF2 $\alpha$ [127]. In other words, the GEF activity of eIF2B towards eIF2 $\alpha$ can be suppressed by eIF2 $\alpha$ phosphorylation.

Other studies have also showed that tumorigenesis and progression in mouse models are enhanced when the phosphorylation of eIF2 $\alpha$ was inhibited through interfering with the expression of the eIF $2 \alpha$ upstream kinase or by a phosphorylation negative eIF $2 \alpha$ mutant $[10,128]$. Therefore, the elevated eIF $2 \alpha$ phosphorylation induced by some stress stimuli usually results in decreased proliferative capability of cancer cells through inhibiting global protein synthesis. Moreover, the increased expression level of eIF2 $\alpha$ has been identified in the malignant lymphocytes from patients with nonHodgkin's lymphoma subtypes (Table 1) [109]. It was also found that eIF2 $\alpha$ expression is significantly increased in both benign and malignant melanocytic tumors, where elevated levels of eIF $2 \alpha$ may drive cancer initiation, but are insufficient to promote malignant progression [110]. Conversely, when neurocytoma is considered, the phosphorylation of eIF2 $\alpha$ has not been found to be associated with benign or malignant brain cancers [129], and in some animal models, inactivating PKR (double-stranded RNA-dependent protein kinase), an upstream kinase of eIF2 $\alpha$ through genetic mutation of its catalytic domain, has no effect on cancer progression [10]. Therefore, the functions of eIF $2 \alpha$ and its phosphorylation in cancer remain unclear, and may depend on stage and grade of cancers. A hypothesis for this puzzle is that the level of eIF $2 \alpha$ phosphorylation is increased in the early stages of cancers in order to respond to serious microenvironmental stresses to reduce protein synthesis and facilitates cancer cell survival [10].

\section{elF2 as a potential target for cancer}

eIF2 $\alpha$ can be phosphorylated by several kinases in response to distinct forms of stress, finally resulting in the global inhibition of protein expression, but paradoxically accompanied with the increased and selective translation of a subset of mRNAs encoding proteins that promote cellular adaptations. However, the sustained phosphorylation of eIF2 $\alpha$ induced by PKR, PERK (PKR-like ER kinase), or 
Table 1 Aberrant expression of elFs in human cancer

\begin{tabular}{lll}
\hline elFs & Dysregulation & Type of cancer \\
\hline $\begin{array}{l}\text { elF1A } \\
\text { elF1AX }\end{array}$ & Mutation & $\begin{array}{l}\text { Uveal melanomas, papillary thyroid carcinoma (PTC), anaplastic thyroid carcinomas (ATC), leptomeningeal } \\
\text { melanocytic neoplasms (LMNs) [2, 108] }\end{array}$ \\
elF2a & Overexpression & $\begin{array}{l}\text { Non-Hodgkin's lymphoma, melanocytic neoplasm, NSCLC, gastrointestinal cancer, and brain tumor } \\
{[2,109,110]}\end{array}$ \\
elF3a & Overexpression & Brain cancer, cervix cancer, lung cancer, stomach cancer and colorectal cancer [2, 10] \\
elF3C & Overexpression & Meningioma and testicular seminoma [2] \\
elF3e & Downregulation & Breast cancer, NSCLC and prostate cancer [2, 111] \\
elF3f & Downregulation & Melanocytic neoplasm, pancreatic cancer, breast and ovary cancer [2, 112, 113] \\
elF3h & Overexpression & Breast cancer, prostate cancer, hepatocellular carcinoma, NSCLC and colorectal cancer [2, 111, 114-119] \\
elF4E & Overexpression/ & Breast cancer, lung cancer, prostate cancer, colorectal cancer, skin cancer, head and neck cancer and \\
elF5A & hyperphosphorylation & Cervical cancer [2, 120-125] \\
elF6 & Overexpression & Cervical cancer, NSCLC and colorectal cancer [2, 126] \\
\hline
\end{tabular}

HRI (heme regulated inhibitor kinase) causes cell apoptosis. Therefore, elevating the level of eIF $2 \alpha$ phosphorylation would be a promising strategy to treat cancer. Using a cell base, BTdCPU and related $N, N$-diarylureas were shown to activate HRI and phosphorylate eIF $2 \alpha$, displaying attractive antitumor effects in vitro and in vivo [130, 131] (Fig. 5a).

Another strategy to increase the phosphorylation of eIF $2 \alpha$ is the use of phosphatase inhibitors, such as salubrinal and guanabenz (Fig. 5b and Fig. 5c). Salubrinal was identified as a selective phosphatase complexes inhibitor and inhibited ER (endoplasmic reticulum) stress-mediated apoptosis [132]. However, the sustained hyperphosphorylation of eIF2 $\alpha$ with high doses of salubrinal treatment resulted in cancer cells apoptosis [133]. Guanabenz, a selective agonist for alpha-2 adrenoceptor used as an antihypertensive drug, binds to a regulatory subunit of protein phosphatase 1 , selectively inhibiting the stress induced-dephosphorylation of eIF2 $\alpha$ [134]. Guanabenz was reported to increase the survival of Hela cells exposed to cytotoxic ER stress, while it attenuated the malignant phenotype and tumor growth in mouse models of breast cancer [135]. In addition, eIF2-GTP-Met-tRNAi ${ }^{\text {Met }}$ ternary complex is also a potential target for the inhibition of translation initiation, NSC119889 and NSC119893, brominated derivatives of fluorescein, have been found to directly target ternary complex formation and prevent the binding of tRNAi ${ }^{\mathrm{Met}}$ to eIF2 (Fig. 5d and e) [136].

\section{elF2B mis-regulation in human cancer}

eIF2B, a GEF for eIF2, is considered to be the master regulator of translation initiation and composed of five subunits $(\alpha, \beta, \gamma, \delta$ and $\varepsilon)$ which are encoded by genes eIF2B1, eIF2B2, eIF2B3, eIF2B4 and eIF2B5, respectively [137]. The mutations in the eIF2B2 and eIF2B5 genes have been reported to be the cause of an inherited disease called vanishing white matter (VWM) [138]. Later, it was found that mutant eIF2B $\varepsilon$ protein results in the deficiency of astrocyte function, and further contributes to the loss of white matter in VWM leukodystrophy [139]. As the largest subunit, eIF2B $\varepsilon$ contains the catalytic domain and promotes GDP/GTP exchange on eIF2. Additionally, eIF $2 \mathrm{~B} \varepsilon$ is found to be upregulated in live cancer and its expression is related to histologic grade, clinical stage and vital status. Furthermore, high eIF2Be expression correlates with poor prognosis and is an independent risk factor for liver cancer, while the downregulation of eIF2Be expression leads to reduction in GEF activity and global protein synthesis, as well as significant reduction in cell growth rate, colony formation and tumor progression in nude mice [140].

\section{elF3 complex mis-regulation in human cancer}

The eIF3 complex is the largest and most complex initiation factor and has 13 isoforms known as eIF3a to eIF3m, which are organized in various combinations to assemble the eIF3 complex. Of these eIF3a, eIF3b, eIF3c, eIF3e, eIF3f and eIF3h are the central subunits of eIF3 complex [141]. Its important functions in protein synthesis endows eIF3 complex with a prominent role in tumorigenesis. The overexpression of eIF3 complex subunits including eIF3a, eIF3b, eIF3c, eIF3h and eIF3i individually promotes the malignant transformation of fibroblast cells by stimulating global protein synthesis and the translation of specific mRNAs encoding growth regulators [142].

Both eIF3a and eIF3c have been found to be overexpressed in various cancers (Table 1) [10]. However, our previous studies have indicated that eIF3a inhibits C-Raf activation and that the down-regulated expression of eIF3a by small interfering RNA promotes ERK activation. Thus, these observations lead to the interesting hypothesis that mitogenic signaling may be regulated by free subunits of translation factors in order to make sure that the cellular response to mitogenic stimulation remains 


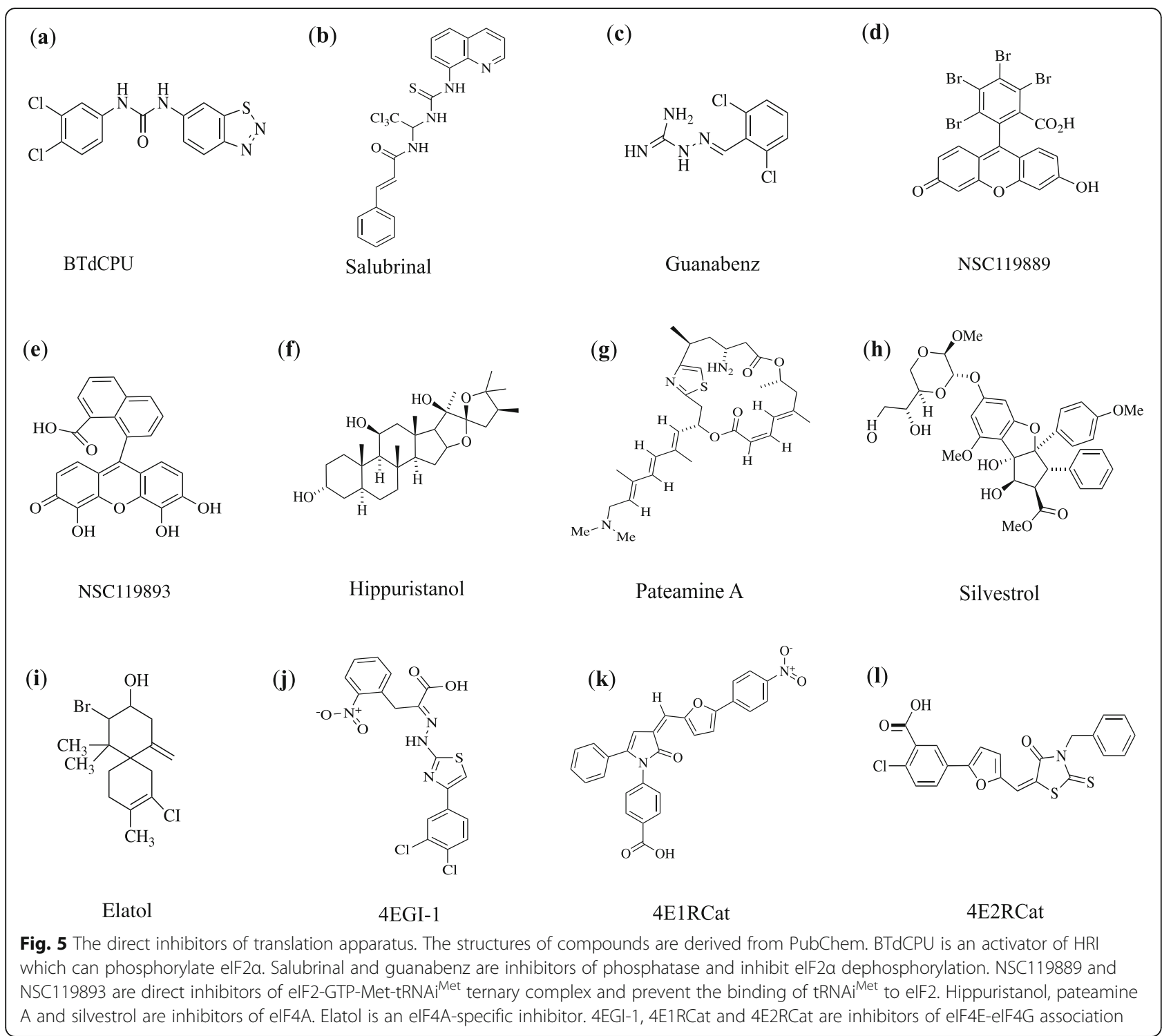

consistent with the cellular capability of protein synthesis [143].

Regarding eIF3h, it has been observed to be frequently amplified along with the proto-oncogene $M y c$ in breast and prostate cancer. Additionally, the levels of eIF3h expression are positively associated with the poor differentiation and aggressive growth of prostate cancer [114]. Likewise, the increased expression of eIF3h was related to proliferation, migration and invasion of human hepatomas [115]. The magnification of the eIF3h gene has been identified in colorectal cancers and non-small cell lung cancer (NSCLC) through Genome-wide analyses and fluorescence in situ hybridization (FISH), respectively (Table 1) [111, 116-118]. More importantly, eIF3h and Myc coamplification markedly improve the response and survival of NSCLC patients treated with epidermal growth factor receptor (EGFR) tyrosine kinase inhibitor such as gefitinib
[119]. eIF3e locus was originally identified as the integration region of mouse mammary tumor virus (MMTV), resulting in the production of a truncated mutant version of eIF3e in mammary epithelial cells, alveolar epithelial cells and mouse embryonic fibroblast cell line, where it leads to the malignant transformation of cells [144]. The reduced expression of eIF3e has also been reported in 37\% of patients with breast cancer and $31 \%$ of NSCLC patients (Table 1) [145]. On the contrary, the overexpression of wild-type full-length eIF3e do not promote malignant transformation, indicating a possible tumor suppressor role for wild type eIF3e and an oncogenic potential of truncated eIF3e.

eIF3f is the only central component of eIF3 complex which has been found to be down-regulated in melanoma and pancreatic cancer (Table 1). Enforced overexpression of eIF3f inhibits protein synthesis and cell proliferation, 
and induced apoptosis in melanoma and pancreatic cancer [112], whereas knocking down the expression of eIF3f protects melanoma cells from apoptosis, indicating eIF3f may function as a negative regulator for translation. Indeed, the reduced transcription levels of eIF3f mRNA are usually detected in tumors including breast cancer, pancreatic cancer, ovarian cancer and melanomas [113]. Therefore, these results suggest that eIF3e and eIF3f may function as negative regulators of mRNA translation.

\section{elF4F complex mis-regulation in human cancer}

It is universally acknowledged that eIF4F plays a key role in the Cap-dependent mRNA translation [2] and indeed the abnormal activity of eIF4F complex has been detected in many tumors, resulting in the selective expression of proteins involved in tumorigenesis and metastasis [7]. As mentioned above, the eIF4F complex is composed of eIF4E (a small Cap-binding protein), eIF4A (an ATPdependent RNA helicase) and a large scaffolding protein eIF4G. eIF4G associates with eIF4A and eIF4E and provides a scaffold which is necessary for the formation and activity of eIF4F complex [24]. The functions of the eIF4F complex are strictly regulated by several of its interacting proteins, such as the eIF4A-binding protein eIF4B, eIF4H and PDCD4, and eIF4E-binding proteins 4E-BPs.

eIF4B and eIF4H activate eIF4A [2], whereas PDCD4 suppresses eIF4A activity [47]. 4E-BPs are inhibitory protein for eIF4E [26]. PABP is a binding protein for eIF4G. As discussed above, the functions of the eIF4F complex in mRNA translation are directly controlled by several signaling pathways which potentially lead to tumor development and progression. eIF4E, the core subunit of eIF4F complex, is frequently overexpressed in many human cancer and most closely correlated with tumorigenesis and metastasis.

eIF4E functions involved in translation are regulated by its availability or expression levels and its phosphorylation at Ser209. The availability of eIF4E and its phosphorylation are regulated by $4 \mathrm{E}-\mathrm{BPs}$ and eIF4G-associated kinases MNK1 and MNK2, respectively. The 4E-BPs compete with eIF4G for its binding site on eIF4E, the binding of $4 \mathrm{E}-\mathrm{BPs}$ to eIF4E is reversible and regulated by mTORC1-dependent phosphorylation of 4E-BPs, thus when phosphorylated by mTORC1, hyperphosphorylated 4E-BPs are incapable of binding eIF4E, enabling the association of eIF4E with eIF4G and the formation of eIF4F complex [30]. Elevated levels of phosphorylated 4E-BP1, which are suggestive of higher levels of eIF4F complex, were detected in advanced prostate cancer [146, 147]. Similarly, reduced 4E-BP1 expression and elevated levels of 4E-BP1 phosphorylation in some cancers were positively correlated with higher grade tumors and reduced survival $[148,149]$. The phosphorylation of eIF4E is promoted by its interacting protein eIF4G, which recruits MNK1 and MNK2 to phosphorylate eIF4E [150].
Several compelling lines of evidence from animal studies indicate that the elevated levels of eIF4E phosphorylation are closely related to the development and progression of cancer [81, 151, 152]. Perhaps the most direct evidence to support the role of eIF4E phosphorylation in cancer was obtained from a series of eIF4E or MNK1/2 mutants which were used to test their contribution to the lymphoma tumorigenesis in the $\mathrm{E} \mu$-Myc transgenic mouse lymphoma model [82]. Mice treated with cells stably expressing the eIF4E S209A mutant that eliminates eIF4E phosphorylation were defective at promoting tumorigenesis. By contrast, a reciprocal phosphomimetic serine to aspartic acid mutation induced accelerated tumor onset which is comparable to that of wild type eIF4E [82]. Furthermore, a dominant negative MNK1 mutant which is unable to phosphorylate eIF4E inhibited the in vivo proliferation of tumor cells promoted by mutations that lead to the deregulation of protein synthesis [82].

The phosphorylation of eIF4E did not significantly increase global protein synthesis but stimulated the expression of anti-apoptotic and pro-invasion proteins [82, 151, 153]. The inhibition of eIF4E has been shown to have therapeutic potential for the treatment of several types of cancer [154-158]. Additionally, the overexpression of eIF4E has been found in breast [117], lung [120], prostate [121], colorectal [122], skin [123], head and neck [124], and cervical cancers (Table 1) [125], and elevated expression levels of eIF4E are strongly related to poor prognosis and decreased survival.

\section{elF4F complex as a potential target for cancer therapy}

There are several strategies to develop drugs that impede the functions of eIF4F complex: (1) inhibiting eIF4A helicase activity, (2) blocking eIF4E binding to the $\mathrm{m}^{7}$ GpppN cap structure, (3) uncoupling eIF4E- eIF4G association, (4) inhibiting eIF4E expression.

\section{Inhibitors of elF4A}

One way to limit eIF4F complex-dependent translation initiation is to target eIF4A, the only known enzymatic component of the complex. There are three smallmolecule compounds, hippuristanol, pateamine A and silvestrol, which have been extensively characterized as inhibitors of eIF4A, and are currently being developed as potential chemotherapies (Fig. 5f-h). Hippuristanol is an allosteric inhibitor of eIF4A, it allosterically inhibits the binding of both free eIF4A and bound eIF4A in the eIF4F complex to RNA, which in turn blocks eIF4A helicase and ATPase activities [159]. Pateamine A and silvestrol, paradoxically promote the RNA-binding ability, ATPase and helicase activities of eIF4A, while then the RNA-binding affinity of eIF4A is in a non-sequence-specific manner, leading to the removal of eIF4A from the eIF4F complex by RNA-mediated sequestration of eIF4A. Pateamine A is 
an irreversible translation inhibitor, probably duo to its covalent inhibition of eIF4A activity, and therefore shows strong toxicity in vivo [160, 161]. However, less toxic pateamine derivatives have been developed [162, 163]. In terms of preclinical efficacy, silvestrol has the highest potency in vivo and is the best-understood eIF4A inhibitor, mainly because of its better pharmacological tolerance and lower non-specific toxicity [164]. Elatol, a marine natural compound, is a novel eIF4A-specific inhibitor which functions through binding the target at key sites in the helicase core of eIF4A and shows broad activity against multiple tumor types (Fig. 5i) [165].

\section{Inhibitors of elF4E-cap interaction}

eIF4E-mediated malignant transformation is in capdependent manner, because overexpression of eIF4E mutant with cap-binding defect shows no transforming and tumorigenic potential. Therefore the cap analogs are classical inhibitors of eIF4E-cap association. The original cap analogs are $\mathrm{m}^{7} \mathrm{GDP}, \mathrm{m}^{7} \mathrm{GTP}$ or their derivates. Presently, about 80 analogs have been synthesized and have been exhaustively tested in vitro and in vivo [166]. However, these cap analogs usually show poor cell membrane permeability and instability in vivo [167]. To solve this dilemma, "pronucleotides" with attractive pharmacokinetic advantages have been synthesized. N-7-benzyl guanosine monophosphate tryptamine phosphoramidate pronucleotide, dubbed 4Ei-1, was shown to inhibit eIF4E-cap dependent translation and enhance chemosensitivity to gemcitabine. Another nucleoside analog, ribavirin, was also reported to be an eIF4E-cap inhibitor and an anti-eIF4E cancer therapeutic. Ribavirin is the first eIF4E inhibitors applied in clinical studies and showed benefits for patients with acute myeloid leukaemia [168] and has been approved by FDA (Food and Drug Administration) in the treatment of RSV (respiratory syncytial virus) and $\mathrm{HCV}$ (hepatitis $\mathrm{C}$ virus).

\section{Inhibitor of elF4E-elF4G interaction}

Another strategy to block eIF4E functions is to discover and design small molecule inhibitors that would interference with eIF4E-eIF4G interaction. Three inhibitors of eIF4E-eIF4G association, 4EGI-1, 4E1RCat and 4E2RCat, were identified by high-throughput screening of chemical libraries [169] (Fig. 5j-l). These molecules inhibited cap-dependent translation and exhibited activity against multiple cancer cell lines [169]. Recently, structural studies of eIF4E and 4EGI-1 complex showed that 4EGI-1 allosterically modify eIF4E by binding to its hydrophobic pocket which is distant from the eIF4G binding site. So eIF4E undergoes localized conformational changes, resulting in the suppression of eIF4EeIF4G association [170].

\section{Targeting elF4E production with antisense oligonucleotides} (ASOs)

Early researches using antisense oligonucleotides (ASOs)based approaches to target eIF4E synthesis showed the feasibility of suppressing eIF4E expression to inhibit tumorigenesis, but accompanied with short half-life of these ASOs in vivo [171, 172]. Subsequently, novel ASOs with the second-generation back-bone antisense modifications were developed. These second-generation ASOs can overcome such drawbacks by incorporating multiple sugarphosphate backbone modifications to improve nuclease resistance and promote stability in tissue. The results of second-generation ASOs targeting eIF4E are encouraging, these ASOs effectively suppressed eIF4E expression in tumors, and greatly attenuate tumor burden in breast and prostate xenograft models. Furthermore, no apparent toxicity was detected [172]. This was attributed to a relatively minimal impact on global protein synthesis (less than $20 \%$ reduction), especially the decrease in expression of proteins involved in proliferation, survival, metastasis and encoded by eIF4E-sensitive mRNA [172]. Additionally, mouse models with long-term inducible suppression of eIF4E indicated that eIF4E suppression is well bearable for many tissues and are completely reversible without any significant negative impact on the life and health of mice [173]. Taken together, these results indicate that targeting eIF4E production directly may be an attractive strategy toward effective therapy for the treatment of tumors.

\section{elF5A mis-regulation in human cancer}

eIF5A is an essential component of the translation initiation apparatus, acting as a GAP for eIF2-GTP, and has also been newly assigned functions in elongation [4]. eIF5A has two isoforms, eIF5A1 and eIF5A2, which are expressed from distinct but related genes. Of note, the amino acid Hypusine is found in eIF5A, presumably due to a special eIF5A post-translation modification pattern. It is essential for most known eIF5A activities and is recognized as a novel potential therapeutic target in the treatment of BCR-BAL-positive leukemias [174].

eIF5A is clearly a factor required for stimulating protein synthesis. Rapid depletion of eIF5A in vivo promptly lead to a 2-fold decrease in protein synthesis in Saccharomyces cerevisiae, whereas treatment a eIF5A-depleted lysate with purified eIF5A stimulated an approximate 2fold increase in protein synthesis, which is dependent on new initiation, suggesting that eIF5A functions at or near the initiation step to stimulate the formation of the first peptide bond in protein synthesis [126].

Furthermore, eIF5A was showed to activate the peptidyl transferase of ribosomes, especially for the synthesis of polyproline by alleviating ribosomal stalling on polyproline sequences [175]. Recently, it was found that knockdown of eIF5A lead to global translation elongation and termination 
defects and also that eIF5A was able to alleviate stalling on many motifs besides polyproline tracts [176].

\section{elF6 complex mis-regulation in human cancer} eIF6 is a rate-limiting factor for mRNA translation initiation, cell growth and transformation [177]. It functions as a ribosomal anti-association factor in translation initiation through blocking the interaction between the $40 \mathrm{~S}$ and $60 \mathrm{~S}$ ribosomal subunits, namely, impeding the formation of $80 \mathrm{~S}$ subunits without mRNA. However, nucleolar eIF6 and cytoplasmic eIF6 are required for the biogenesis of $60 \mathrm{~S}$ subunits and growth factor-stimulated translation, respectively [178]. Furthermore, an increasing number of studies have demonstrated that there is a highly aberrant expression of eIF6 in various types of human cancer including colorectal cancer, head and neck carcinoma, malignant mesothelioma, acute promyelocytic leukemia and NSCLC (Table 1) [2, 179]. Therefore, modulation of eIF6 activity or expression may exert an innovative treatment for cancers. In a murine model of lymphomagenesis, the impairment of cytoplasmic eIF6 activity leads to the inhibition of lymphomagenesis and tumor progression as well as a striking increase of survival without adverse effects [180, 181].

\section{Conclusions}

Over the last two decades, notable progress has been achieved towards understanding how oncogenic signaling pathways, including Ras-MAPK and PI3K-Akt, regulate the components of translation initiation apparatus and subsequent mRNA translation in eukaryotic cells. This is particularly important, as the translation initiation factors are often primary targets of these signaling pathways, which include several oncogenes and are misregulated in cancers, making abnormal translation an universal characteristic of cancer cells with different genetic make-up. Almost all these signaling pathways employ mTOR to regulate the functions of eIFs and mTOR is recognized as the master regulator of protein synthesis. The changes in the expression of certain translation initiation factors (mostly increased expression) are related to the development and progress of specific cancers. In this context, multiple components of several oncogenic signaling pathways and translation initiation factors involved in mRNA translation have been identified as biomarkers with potential diagnostic, therapeutic and prognostic utility. Therefore, anti-tumor agents targeting the core components of protein synthesis and related signaling pathways represent novel promising anticancer drugs and can get over intra-tumor heterogeneity. The initial successes of therapeutics that target dysregulation of mRNA translation in cancer suggest promising potential in their transition from the bench to the bedside in the near future.

\section{Abbreviations}

4E-BP1: 4E-binding protein 1; 5'UTR: 5' untranslated region; AMPK: AMPactivated protein kinase; ASOs: Antisense oligonucleotides; CASTOR1/ 2: Cellular arginine sensor for mTORC1 complex1/2; CDK1: Cyclin Dependent Kinase 1; Deptor: DEP domain-containing mTOR-interacting protein; eEF2K: eukaryotic elongation factor 2 kinase; EGFR: Epidermal growth factor receptor; elFs: eukaryotic initiation factors; FISH: Fluorescence in situ hybridization; GAP: GTPase activating protein; GATOR1: GAP activity towards Rags 1; GßL: GTPase $\beta$-subunit like protein; GEF: Guanine nucleotideexchange factor; GPCRs: G protein-coupled receptors; GSK: Glycogen synthase kinase; HIF1a: Hypoxia-inducible factor 1a; HCV: Hepatitis C virus; HRI: Heme regulated inhibitor kinase; IGF: Insulin-like growth factor; IRS1: Insulin receptor substrate 1; JNKs: C-Jun N-terminal kinases; MAP 2 K: MAPK kinase; MAP3K: MAPK kinase kinase; MAPK: Mitogen-activated protein kinase; mLST8: mammalian lethal with Sec13 protein 8; MMTV: Mouse mammary tumor virus; MNKs: MAPK-interacting kinases; mRNA: messenger RNA; NSCLC: Non-small cell lung cancer; mTOR: mammalian target of rapamycin; mTORC1: mTOR complex 1; mTORC2: mTOR complex 2; PABP: Poly (A)-binding protein;

PDK1: Phosphoinositide-dependent kinase 1; PDCD4: Programmed cell death 4 protein; PERK: PKR-like ER kinase; PKC: Protein kinase C;

PI3K: Phosphatidylinositol 3-kinase; PIP2: Phosphatidylinositol (3,4)-bisphosphate; PIC: Pre-initiation complex; PIP3: Phosphatidylinositol $(3,4,5)$-trisphosphate; REDD1: Regulated in development and DNA damage response: Raptor: Regulatory protein activated with mTOR; Rheb: Ras homologue enriched in brain; Rictor: Rapamycin insensitive companion of mTOR; rpS6: ribosomal protein S6; RSK: Ribosomal S6 kinase; RSV: Respiratory syncytial virus; RTKs: Receptor tyrosine kinases; SGK: Serum glucose kinase; TOP: Terminal oligopyrimidine motif; TSC: Tuberous sclerosis complex; VEGF: Vascular endothelial growth factor

\section{Acknowledgements}

The authors appreciate other members of our laboratories including Drs. Yang Yang and Xiaoxi Guo for their critical reviewing our manuscript and apologize to our colleagues whose contributions were not cited due to space limitations.

\section{Authors' contributions}

Conception and design: SA, TRX; Writing: SA, PQH, JJY and RW; Review and revision of the manuscript: TRX, YL, QH and RW. All authors read and approved the final manuscript.

\section{Funding}

This work was funded by the National Natural Science Foundation of China (No. 81760264; No. 81960394; No. 81560455; No. 81473342), Natural Science Foundation of Yunnan Province (2017FB045) and conducted in the University Based Provincial Key Laboratory of Screening and Utilization of Targeted Drugs.

Availability of data and materials

Not applicable' for this section.

Ethics approval and consent to participate

Not applicable' for this section.

Consent for publication

Not applicable' for this section.

\section{Competing interests}

The authors declare no competing financial interests.

\section{Author details}

${ }^{1}$ Faculty of Environmental Science and Engineering, Kunming University of Science and Technology, 727 Jingming South Road, Kunming 650500, China. ${ }^{2}$ Faculty of Life Science and Technology, Kunming University of Science and Technology, Kunming 650500, China. ${ }^{3}$ Molecular Pharmacology Group, Institute of Molecular, Cell and Systems Biology, College of Medical, Veterinary and Life Sciences, University of Glasgow, Glasgow G12 8QQ, Scotland, UK. 
Received: 8 January 2020 Accepted: 1 June 2020 Published online: 04 November 2020

\section{References}

1. Verma M, Choi J, Cottrell KA, Lavagnino Z, Thomas EN, Pavlovic-Djuranovic $S$, et al. A short translational ramp determines the efficiency of protein synthesis. Nat Commun. 2019;10:5774.

2. Ali MU, Ur Rahman MS, Jia Z, Jiang C. Eukaryotic translation initiation factors and cancer. Tumor Biol. 2017;39:1010428317709805.

3. Bramham CR, Jensen KB, Proud CG. Tuning Specific Translation in Cancer Metastasis and Synaptic Memory: Control at the MNK-elF4E Axis. Trends Biochem Sci. 2016;41:847-58.

4. Mathews MB, Hershey JWB. The translation factor elF5A and human cancer. Biochim Biophys Acta. 1849;2015:836-44.

5. Pelletier J, Graff J, Ruggero D, Sonenberg N. Targeting the elF4F translation initiation complex: a critical nexus for cancer development. Cancer Res. 2015;75:250-63.

6. Yin J-Y, Zhang J-T, Zhang W, Zhou H-H, Liu Z-Q. elF3a: A new anticancer drug target in the elF family. Cancer Lett. 2018;412:81-7.

7. Malka-Mahieu H, Newman M, Desaubry L, Robert C, Vagner S. Molecular Pathways: The elF4F Translation Initiation Complex-New Opportunities for Cancer Treatment. Clin Cancer Res. 2017:23:21-5.

8. Jackson RJ, Hellen CUT, Pestova TV. The mechanism of eukaryotic translation initiation and principles of its regulation. Nat Rev Mol Cell Biol. 2010;11:113-27.

9. Llacer JL, Hussain T, Saini AK, Nanda JS, Kaur S, Gordiyenko Y, et al. Translational initiation factor elF5 replaces elF1 on the 405 ribosomal subunit to promote start-codon recognition. eLife. 2018;7:e39273.

10. Silvera D, Formenti SC, Schneider RJ. Translational control in cancer. Nat Rev Cancer. 2010;10:254-66.

11. Sengupta S, Peterson TR, Sabatini DM. Regulation of the mTOR Complex 1 Pathway by Nutrients, Growth Factors, and Stress. Mol Cell. 2010;40:310-22

12. Kim LC, Cook RS, Chen J. mTORC1 and mTORC2 in cancer and the tumor microenvironment. Oncogene. 2017;36:2191-201.

13. Nojima H, Tokunaga C, Eguchi S, Oshiro N, Hidayat S, Yoshino K, et al. The mammalian target of rapamycin (mTOR) partner, raptor, binds the mTOR substrates p70 S6 kinase and 4E-BP1 through their TOR signaling (TOS) motif. J Biol Chem. 2003;278:15461-4.

14. Guertin DA, Stevens DM, Thoreen CC, Burds AA, Kalaany NY, Moffat J, et al. Ablation in mice of the $\mathrm{mTORC}$ components raptor, rictor, or $\mathrm{mLST}$ 8 reveals that mTORC2 is required for signaling to Akt-FOXO and PKCalpha, but not S6K1. Dev Cell. 2006;11:859-71.

15. Peterson TR, Laplante M, Thoreen CC, Sancak Y, Kang SA, Kuehl WM, et al. DEPTOR is an mTOR inhibitor frequently overexpressed in multiple myeloma cells and required for their survival. Cell. 2009;137:873-86.

16. Yang $H$, Jiang $X$, Li B, Yang HJ, Miller M, Yang A, et al. Mechanisms of mTORC1 activation by RHEB and inhibition by PRAS40. Nature. 2017;552: 368-73.

17. Vander Haar E, Lee S-I, Bandhakavi S, Griffin TJ, Kim D-H. Insulin signalling to mTOR mediated by the Akt/PKB substrate PRAS40. Nat Cell Biol. 2007:9:31623

18. Sancak Y, Bar-Peled L, Zoncu R, Markhard AL, Nada S, Sabatini DM Ragulator-Rag complex targets mTORC1 to the lysosomal surface and is necessary for its activation by amino acids. Cell. 2010;141:290-303.

19. Mossmann D, Park S, Hall MN. mTOR signalling and cellular metabolism are mutual determinants in cancer. Nat Rev Cancer. 2018;18:744-57.

20. Fan Q, Aksoy O, Wong RA, Ilkhanizadeh S, Novotny CJ, Gustafson WC, et al. A Kinase Inhibitor Targeted to mTORC1 Drives Regression in Glioblastoma. Cancer cell. 2017;31:424-35.

21. Kang SA, Pacold ME, Cervantes CL, Lim D, Lou HJ, Ottina K, et al. mTORC1 phosphorylation sites encode their sensitivity to starvation and rapamycin. Science. 2013;341:1236566

22. Rodrik-Outmezguine VS, Okaniwa M, Yao Z, Novotny CJ, McWhirter C, Banaji $A$, et al. Overcoming mTOR resistance mutations with a new-generation mTOR inhibitor. Nature. 2016:534:272-6.

23. Hinnebusch AG. The scanning mechanism of eukaryotic translation initiation. Annu Rev Biochem. 2014;83:779-812.

24. Parsyan A, Svitkin Y, Shahbazian D, Gkogkas C, Lasko P, Merrick WC, et al. mRNA helicases: the tacticians of translational control. Nat Rev Mol Cell Biol. 2011;12:235-45.
25. Sonenberg N, Hinnebusch AG. Regulation of Translation Initiation in Eukaryotes: Mechanisms and Biological Targets. Cell. 2009;136:731-45.

26. Pause A, Belsham GJ, Gingras AC, Donzé O, Lin TA, Lawrence JC, et al. Insulin-dependent stimulation of protein synthesis by phosphorylation of a regulator of 5'-cap function. Nature. 1994;371:762-7.

27. Gingras AC, Gygi SP, Raught B, Polakiewicz RD, Abraham RT, Hoekstra MF, et al. Regulation of 4E-BP1 phosphorylation: a novel two-step mechanism. Genes Dev. 1999;13:1422-37.

28. Gingras AC, Raught B, Gygi SP, Niedzwiecka A, Miron M, Burley SK, et al. Hierarchical phosphorylation of the translation inhibitor 4E-BP1. Genes Dev. 2001;15:2852-64.

29. Armengol G, Rojo F, Castellvi J, Iglesias C, Cuatrecasas M, Pons B, et al. 4Ebinding protein 1: a key molecular 'funnel factor' in human cancer with clinical implications. Cancer Res. 2007;67:7551-5.

30. Roux PP, Topisirovic I. Signaling Pathways Involved in the Regulation of mRNA Translation. Mol Cell Biol. 2018;38:e0070-18.

31. Ma XM, Blenis J. Molecular mechanisms of mTOR-mediated translational control. Nat Rev Mol Cell Biol. 2009;10:307-18.

32. Zoncu R, Efeyan A, Sabatini DM. mTOR: from growth signal integration to cancer, diabetes and ageing. Nat Rev Mol Cell Biol. 2011;12:21-35.

33. Magnuson B, Ekim B, Fingar DC. Regulation and function of ribosomal protein S6 kinase (S6K) within mTOR signalling networks. Biochem J. 2012 441:1-21.

34. Fenton TR, Gout IT. Functions and regulation of the 70kDa ribosomal S6 kinases. Int J Biochem Cell Biol. 2011:43:47-59.

35. Gout I, Minami T, Hara K, Tsujishita Y, Filonenko V, Waterfield MD, et al. Molecular cloning and characterization of a novel p70 S6 kinase, p70 S6 kinase beta containing a proline-rich region. J Biol Chem. 1998;273:30061-4.

36. Pende M, Um SH, Mieulet V, Sticker M, Goss VL, Mestan J, et al. S6K1(-/)/S6K2(-/-) mice exhibit perinatal lethality and rapamycin-sensitive 5'terminal oligopyrimidine mRNA translation and reveal a mitogen-activated protein kinase-dependent S6 kinase pathway. Mol Cell Biol. 2004;24:311224.

37. Ohanna M, Sobering AK, Lapointe $T$, Lorenzo L, Praud C, Petroulakis E, et al. Atrophy of S6K1(-/-) skeletal muscle cells reveals distinct mTOR effectors for cell cycle and size control. Nat Cell Biol. 2005;7:286-94.

38. Holz MK. The role of S6K1 in ER-positive breast cancer. Cell cycle. 2012;11: 3159-65.

39. Pardo OE, Wellbrock C, Khanzada UK, Aubert M, Arozarena I, Davidson S, et al. FGF-2 protects small cell lung cancer cells from apoptosis through a complex involving PKCepsilon, B-Raf and S6K2. EMBO J. 2006;25:3078-88.

40. Shin S, Wolgamott L, Yu Y, Blenis J, Yoon S-O. Glycogen synthase kinase (GSK)-3 promotes p70 ribosomal protein S6 kinase (p70S6K) activity and cell proliferation. Proc Natl Acad Sci U S A. 2011;108:e1204-13.

41. Roux PP, Shahbazian D, Vu H, Holz MK, Cohen MS, Taunton J, et al. RAS/ERK signaling promotes site-specific ribosomal protein $\mathbf{S 6}$ phosphorylation via RSK and stimulates cap-dependent translation. J Biol Chem. 2007:282: 14056-64.

42. Ruvinsky I, Sharon N, Lerer T, Cohen H, Stolovich-Rain M, Nir T, et al. Ribosomal protein $\mathrm{S} 6$ phosphorylation is a determinant of cell size and glucose homeostasis. Genes Dev. 2005;19:2199-211.

43. Shahbazian D, Roux PP, Mieulet V, Cohen MS, Raught B, Taunton J, et al The mTOR/PI3K and MAPK pathways converge on elF4B to control its phosphorylation and activity. EMBO J. 2006;25:2781-91.

44. Kenney JW, Moore CE, Wang X, Proud CG. Eukaryotic elongation factor 2 kinase, an unusual enzyme with multiple roles. Adv Biol Regul. 2014;55:15-27.

45. Wang X, Li W, Williams M, Terada N, Alessi DR, Proud CG. Regulation of elongation factor 2 kinase by p90(RSK1) and p70 S6 kinase. EMBO J. 2001;20: 4370-9.

46. Wang X, Regufe da Mota S, Liu R, Moore CE, Xie J, Lanucara F, et al. Eukaryotic elongation factor 2 kinase activity is controlled by multiple inputs from oncogenic signaling. Mol Cell Biol. 2014:34:4088-103.

47. Yang H-S, Jansen AP, Komar AA, Zheng X, Merrick WC, Costes S, et al. The transformation suppressor $\mathrm{Pdcd} 4$ is a novel eukaryotic translation initiation factor 4A binding protein that inhibits translation. Mol Cell Biol. 2003;23:26-37.

48. Dorrello NV, Peschiaroli A, Guardavaccaro D, Colburn NH, Sherman NE, Pagano M. S6K1- and betaTRCP-mediated degradation of PDCD4 promotes protein translation and cell growth. Science. 2006:314:467-71.

49. Cerovac V, Monteserin-Garcia J, Rubinfeld H, Buchfelder M, Losa M, Florio T, et al. The somatostatin analogue octreotide confers sensitivity to rapamycin treatment on pituitary tumor cells. Cancer Res. 2010;70:666-74. 
50. Dibble CC, Cantley LC. Regulation of mTORC1 by PI3K signaling. Trends Cell Biol. 2015;25:545-55.

51. Henske EP, Jozwiak S, Kingswood JC, Sampson JR, Thiele EA. Tuberous sclerosis complex. Nat Rev Dis Prim. 2016;2:16035.

52. Menon S, Dibble CC, Talbott G, Hoxhaj G, Valvezan AJ, Takahashi H, et al. Spatial control of the TSC complex integrates insulin and nutrient regulation of mTORC1 at the lysosome. Cell. 2014;156:771-85.

53. Inoki K, Li Y, XU T, Guan K-L. Rheb GTPase is a direct target of TSC2 GAP activity and regulates mTOR signaling. Genes Dev. 2003;17:1829-34.

54. Bai X, Ma D, Liu A, Shen X, Wang QJ, Liu Y, et al. Rheb activates mTOR by antagonizing its endogenous inhibitor, FKBP38. Science. 2007;318:977-80.

55. Oshiro N, Takahashi R, Yoshino K, Tanimura K, Nakashima A, Eguchi S, et al. The proline-rich Akt substrate of $40 \mathrm{kDa}$ (PRAS40) is a physiological substrate of mammalian target of rapamycin complex 1. J Biol Chem. 2007; 282:20329-39.

56. Thorpe LM, Yuzugullu H, Zhao JJ. PI3K in cancer: divergent roles of isoforms, modes of activation and therapeutic targeting. Nat Rev Cancer. 2015;15:724.

57. Zhang Y, Kwok-Shing Ng P, Kucherlapati M, Chen F, Liu Y, Tsang YH, et al. A Pan-Cancer Proteogenomic Atlas of PI3K/AKT/mTOR Pathway Alterations. Cancer Cell. 2017;31:820-832.e3.

58. Ma L, Chen Z, Erdjument-Bromage H, Tempst P, Pandolfi PP. Phosphorylation and functional inactivation of TSC2 by Erk implications for tuberous sclerosis and cancer pathogenesis. Cell. 2005;121:179-93.

59. Harrington LS, Findlay GM, Gray A, Tolkacheva T, Wigfield S, Rebholz H, et al. The TSC1-2 tumor suppressor controls insulin-PI3K signaling via regulation of IRS proteins. J Cell Biol. 2004;166:213-23.

60. Engelman JA. Targeting PI3K signalling in cancer: opportunities, challenges and limitations. Nat Rev Cancer. 2009;9:550-62.

61. Hennessy BT, Smith DL, Ram PT, Lu Y, Mills GB. Exploiting the PI3K/AKT pathway for cancer drug discovery. Nat Rev Drug Discov. 2005;4:988-1004.

62. De Santis MC, Gulluni F, Campa CC, Martini M, Hirsch E. Targeting PI3K signaling in cancer: Challenges and advances. Biochim Biophys Acta Rev Cancer. 2019;1871:361-6.

63. Hanker AB, Kaklamani V, Arteaga CL. Challenges for the Clinical Development of PI3K Inhibitors: Strategies to Improve Their Impact in Solid Tumors. Cancer Discov. 2019;9:482-91.

64. An S, Yang Y, Ward R, Liu Y, Guo X-X, Xu T-R. Raf-interactome in tuning the complexity and diversity of Raf function. FEBS J. 2015;282:32-53.

65. Dhillon AS, Hagan S, Rath O, Kolch W. MAP kinase signalling pathways in cancer. Oncogene. 2007;26:3279-90

66. Downward J. Targeting RAS signalling pathways in cancer therapy. Nat Rev Cancer. 2003;3:11-22.

67. An S, Yang Y, Ward R, Liu Y, Guo X-X, Xu T-R. A-Raf: A new star of the family of raf kinases. Crit Rev Biochem Mol Biol. 2015:50:520-31.

68. Aguirre-Ghiso JA, Estrada Y, Liu D, Ossowski L. ERK (MAPK) activity as a determinant of tumor growth and dormancy; regulation by p38(SAPK). Cancer Res. 2003;63:1684-95.

69. Johnson GL, Lapadat R. Mitogen-activated protein kinase pathways mediated by ERK, JNK, and p38 protein kinases. Science. 2002;298:1911-2.

70. Buxade M, Parra-Palau JL, Proud CG. The Mnks: MAP kinase-interacting kinases (MAP kinase signal-integrating kinases). Front Biosci. 2008;13:5359-73.

71. Carriere A, Ray H, Blenis J, Roux PP. The RSK factors of activating the Ras/ MAPK signaling cascade. Front Biosci. 2008;13:4258-75.

72. Zeniou M, Ding T, Trivier E, Hanauer A. Expression analysis of RSK gene family members: the RSK2 gene, mutated in Coffin-Lowry syndrome, is prominently expressed in brain structures essential for cognitive function and learning. Hum Mol Genet. 2002;11:2929-40.

73. Fisher TL, Blenis J. Evidence for two catalytically active kinase domains in pp90rsk. Mol Cell Biol. 1996;16:1212-9.

74. Romeo $Y$, Zhang $X$, Roux PP. Regulation and function of the RSK family of protein kinases. Biochem J. 2012:441:553-69.

75. Angenstein F, Greenough WT, Weiler IJ. Metabotropic glutamate receptorinitiated translocation of protein kinase p90rsk to polyribosomes: a possible factor regulating synaptic protein synthesis. Proc Natl Acad Sci U S A. 1998; 95:15078-83.

76. Chung J, Kuo CJ, Crabtree GR, Blenis J. Rapamycin-FKBP specifically blocks growth-dependent activation of and signaling by the $70 \mathrm{kd}$ S6 protein kinases. Cell. 1992;69:1227-36.

77. Galan JA, Geraghty KM, Lavoie G, Kanshin E, Tcherkezian J, Calabrese V, et al. Phosphoproteomic analysis identifies the tumor suppressor PDCD4 as a RSK substrate negatively regulated by 14-3-3. Proc Natl Acad Sci U S A. 2014; 111:E2918-27.

78. Stambolic V, Woodgett JR. Mitogen inactivation of glycogen synthase kinase-3 beta in intact cells via serine 9 phosphorylation. Biochem J. 1994; 303(Pt 3):701-4.

79. Scheper GC, Morrice NA, Kleijn M, Proud CG. The mitogen-activated protein kinase signal-integrating kinase Mnk2 is a eukaryotic initiation factor $4 \mathrm{E}$ kinase with high levels of basal activity in mammalian cells. Mol Cell Biol. 2001:21:743-54.

80. Topisirovic I, Ruiz-Gutierrez M, Borden KLB. Phosphorylation of the eukaryotic translation initiation factor elF4E contributes to its transformation and mRNA transport activities. Cancer Res. 2004;64:8639-42.

81. Proud CG. Mnks, elF4E phosphorylation and cancer. Biochim Biophys Acta Gene Regul Mech. 1849;2015:766-73.

82. Wendel H-G, Silva RLA, Malina A, Mills JR, Zhu H, Ueda T, et al. Dissecting elF4E action in tumorigenesis. Genes Dev. 2007;21:3232-7.

83. Ananieva EA, Wilkinson AC. Branched-chain amino acid metabolism in cancer. Curr Opin Clin Nutr Metab Care. 2018;21:64-70.

84. Bar-Peled L, Sabatini DM. Regulation of mTORC1 by amino acids. Trends Cell Biol. 2014;24:400-6.

85. Kim E, Goraksha-Hicks P, Li L, Neufeld TP, Guan K-L. Regulation of TORC1 by Rag GTPases in nutrient response. Nat Cell Biol. 2008;10:935-45.

86. Sancak $Y$, Peterson TR, Shaul YD, Lindquist RA, Thoreen CC, Bar-Peled L, et al. The Rag GTPases bind raptor and mediate amino acid signaling to mTORC1. Science. 2008:320:1496-501.

87. Binda M, Peli-Gulli M-P, Bonfils G, Panchaud N, Urban J, Sturgill TW, et al. The Vam6 GEF controls TORC1 by activating the EGO complex. Mol Cell. 2009;35:563-73.

88. Sekiguchi T, Hirose E, Nakashima N, Ii M, Nishimoto T. Novel G proteins, Rag C and Rag D, interact with GTP-binding proteins, Rag A and Rag B. J Biol Chem. 2001;276:7246-57.

89. Nada S, Hondo A, Kasai A, Koike M, Saito K, Uchiyama Y, et al. The novel lipid raft adaptor p18 controls endosome dynamics by anchoring the MEKERK pathway to late endosomes. EMBO J. 2009;28:477-89.

90. Bar-Peled L, Chantranupong L, Cherniack AD, Chen WW, Ottina KA, Grabiner BC, et al. A Tumor suppressor complex with GAP activity for the Rag GTPases that signal amino acid sufficiency to mTORC1. Science. 2013;340:1100-6.

91. Saxton RA, Chantranupong L, Knockenhauer KE, Schwartz TU, Sabatini DM. Mechanism of arginine sensing by CASTOR1 upstream of mTORC1. Nature. 2016;536:229-33.

92. Saxton RA, Knockenhauer KE, Wolfson RL, Chantranupong L, Pacold ME, Wang T, et al. Structural basis for leucine sensing by the Sestrin2-mTORC1 pathway. Science. 2016;351:53-8.

93. Wolfson RL, Chantranupong L, Saxton RA, Shen K, Scaria SM, Cantor JR, et al. Sestrin2 is a leucine sensor for the mTORC1 pathway. Science. 2016;351:43-8

94. Chantranupong L, Scaria SM, Saxton RA, Gygi MP, Shen K, Wyant GA, et al. The CASTOR Proteins Are Arginine Sensors for the mTORC1 Pathway. Cell. 2016;165:153-64.

95. Xu D, Shimkus KL, Lacko HA, Kutzler L, Jefferson LS, Kimball SR. Evidence for a role for Sestrin 1 in mediating leucine-induced activation of mTORC1 in skeletal muscle. Am J Physiol Endocrinol Metab. 2019;316:e817-28.

96. Tsun Z-Y, Bar-Peled L, Chantranupong L, Zoncu R, Wang T, Kim C, et al. The folliculin tumor suppressor is a GAP for the RagC/D GTPases that signal amino acid levels to mTORC1. Mol Cell. 2013;52:495-505.

97. Rebsamen M, Pochini L, Stasyk T, de Araujo MEG, Galluccio M, Kandasamy RK, et al. SLC38A9 is a component of the lysosomal amino acid sensing machinery that controls mTORC1. Nature. 2015;519:477-81.

98. Wyant GA, Abu-Remaileh M, Wolfson RL, Chen WW, Freinkman E, Danai LV, et al. mTORC1 Activator SLC38A9 is Required to Efflux Essential Amino Acids from Lysosomes and Use Protein as a Nutrient. Cell. 2017;171:642-654.e12.

99. Gatenby RA, Gillies RJ. Why do cancers have high aerobic glycolysis? Nat Rev Cancer. 2004:4:891-9.

100. Hardie DG, Schaffer BE, Brunet A. AMPK: An Energy-Sensing Pathway with Multiple Inputs and Outputs. Trends Cell Biol. 2016:26:190-201.

101. Xiao B, Sanders MJ, Underwood E, Heath R, Mayer FV, Carmena D, et al. Structure of mammalian AMPK and its regulation by ADP. Nature. 2011;472:230-3.

102. Corradetti MN, Inoki K, Bardeesy N, DePinho RA, Guan K-L. Regulation of the TSC pathway by LKB1: evidence of a molecular link between tuberous sclerosis complex and Peutz-Jeghers syndrome. Genes Dev. 2004;18:1533-8.

103. Laplante M, Sabatini DM. MTOR signaling in growth control and disease. Cell. 2012;149:274-93. 
104. Gwinn DM, Shackelford DB, Egan DF, Mihaylova MM, Mery A, Vasquez DS, et al. AMPK phosphorylation of raptor mediates a metabolic checkpoint. Mol Cell. 2008;30:214-26.

105. Brugarolas J, Lei K, Hurley RL, Manning BD, Reiling JH, Hafen E, et al. Regulation of mTOR function in response to hypoxia by REDD1 and the TSC1/TSC2 tumor suppressor complex. Genes Dev. 2004;18:2893-904.

106. DeYoung MP, Horak P, Sofer A, Sgroi D, Ellisen LW. Hypoxia regulates TSC1/ 2-mTOR signaling and tumor suppression through REDD1-mediated 14-3-3 shuttling. Genes Dev. 2008;22:239-51.

107. Sheikh MS, Fornace AJJ. Regulation of translation initiation following stress. Oncogene. 1999;18:6121-8.

108. Sehrawat U, Koning F, Ashkenazi S, Stelzer G, Leshkowitz D, Dikstein R. Cancer-Associated Eukaryotic Translation Initiation Factor 1A Mutants Impair Rps3 and Rps10 Binding and Enhance Scanning of Cell Cycle Genes. Mol Cell Biol. 2019;39:e00441-004418.

109. Lam N, Sandberg ML, Sugden B. High physiological levels of LMP1 result in phosphorylation of elF2 alpha in Epstein-Barr virus-infected cells. J Virol. 2004;78:1657-64.

110. Rosenwald IB, Wang S, Savas L, Woda B, Pullman J. Expression of translation initiation factor elF-2alpha is increased in benign and malignant melanocytic and colonic epithelial neoplasms. Cancer. 2003;98:1080-8.

111. Choe J, Lin S, Zhang W, Liu Q, Wang L, Ramirez-Moya J, et al. mRNA circularization by METTL3-elF3h enhances translation and promotes oncogenesis. Nature. 2018;561:556-60.

112. Doldan A, Chandramouli A, Shanas R, Bhattacharyya A, Cunningham JT, Nelson MA, et al. Loss of the eukaryotic initiation factor $3 \mathrm{f}$ in pancreatic cancer. Mol Carcinog. 2008;47:235-44.

113. Shi J, Kahle A, Hershey JWB, Honchak BM, Warneke JA, Leong SPL, et al. Decreased expression of eukaryotic initiation factor $3 f$ deregulates translation and apoptosis in tumor cells. Oncogene. 2006;25:4923-36.

114. Zhang L, Smit-McBride Z, Pan X, Rheinhardt J, Hershey JWB. An oncogenic role for the phosphorylated h-subunit of human translation initiation factor elF3. J Biol Chem. 2008;283:24047-60.

115. Zhu Q, Qiao G-L, Zeng X-C, Li Y, Yan J-J, Duan R, et al. Elevated expression of eukaryotic translation initiation factor $3 \mathrm{H}$ is associated with proliferation, invasion and tumorigenicity in human hepatocellular carcinoma. Oncotarget. 2016;7:49888-901.

116. Carvajal-Carmona LG, Cazier J-B, Jones AM, Howarth K, Broderick P, Pittman A, et al. Fine-mapping of colorectal cancer susceptibility loci at 8q23.3, $16 q 22.1$ and 19q13.11: refinement of association signals and use of in silico analysis to suggest functional variation and unexpected candidate target genes. Hum Mol Genet. 2011;20:2879-88.

117. Pettersson F, Yau C, Dobocan MC, Culjkovic-Kraljacic B, Retrouvay H, Puckett R, et al. Ribavirin treatment effects on breast cancers overexpressing elF4E, a biomarker with prognostic specificity for luminal B-type breast cancer. Clin Cancer Res. 2011;17:2874-84

118. Tomlinson IPM, Webb E, Carvajal-Carmona L, Broderick P, Howarth K, Pittman AM, et al. A genome-wide association study identifies colorectal cancer susceptibility loci on chromosomes 10p14 and 8q23.3. Nat Genet. 2008:40:623-30.

119. Cappuzzo F, Varella-Garcia M, Rossi E, Gajapathy S, Valente M, Drabkin H, et al. MYC and EIF3H Coamplification significantly improve response and survival of non-small cell lung cancer patients (NSCLC) treated with gefitinib. J Clin Oncol. 2009:4:472-8.

120. Yoshizawa A, Fukuoka J, Shimizu S, Shilo K, Franks TJ, Hewitt SM, et al. Overexpression of phospho-elF4E is associated with survival through AKT pathway in non-small cell lung cancer. Clin Cancer Res. 2010;16: 240-8.

121. Kremer CL, Klein RR, Mendelson J, Browne W, Samadzedeh LK, Vanpatten K, et al. Expression of mTOR signaling pathway markers in prostate cancer progression. Prostate. 2006;66:1203-12.

122. Berkel HJ, Turbat-Herrera EA, Shi R, de Benedetti A. Expression of the translation initiation factor elF4E in the polyp-cancer sequence in the colon. Cancer Epidemiol Biomarkers Prev. 2001;10:663-6.

123. Jiang $X$, Jiang $X$, Feng $Y, X u R$, Wang $Q$, Deng $H$. Proteomic analysis of elF5B silencing-modulated proteostasis. PLOS ONE. 2016;11:e0168387.

124. Nathan CA, Liu L, Li BD, Abreo FW, Nandy I, De Benedetti A. Detection of the proto-oncogene elF4E in surgical margins may predict recurrence in head and neck cancer. Oncogene. 1997;15:579-84.

125. Wang S, Pang T, Gao M, Kang H, Ding W, Sun X, et al. HPV E6 induces elF4E transcription to promote the proliferation and migration of cervical cancer. FEBS Lett. 2013;587:690-7.
126. Henderson A, Hershey JW. Eukaryotic translation initiation factor (elF) 5A stimulates protein synthesis in Saccharomyces cerevisiae. Proc Natl Acad Sci U S A. 2011;108:6415-9.

127. Pavitt GD, Yang W, Hinnebusch AG. Homologous segments in three subunits of the guanine nucleotide exchange factor elF2B mediate translational regulation by phosphorylation of elF2. Mol Cell Biol. 1997;17: 1298-313.

128. Donze O, Jagus R, Koromilas AE, Hershey JW, Sonenberg N. Abrogation of translation initiation factor elF-2 phosphorylation causes malignant transformation of NIH 3T3 cells. EMBO J. 1995;14:3828-34.

129. Tejada S, Lobo MVT, García-Villanueva M, Sacristán S, Pérez-Morgado MI, Salinas M, et al. Eukaryotic initiation factors (elF) 2alpha and 4E expression localization, and phosphorylation in brain tumors. J Histochem Cytochem. 2009;57:503-12.

130. Chen T, Ozel D, Qiao Y, Harbinski F, Chen L, Denoyelle S, et al. Chemical genetics identify elF2alpha kinase heme-regulated inhibitor as an anticancer target. Nat Chem Biol. 2011;7:610-6.

131. Denoyelle S, Chen T, Chen L, Wang Y, Klosi E, Halperin JA, et al. In vitro inhibition of translation initiation by N,N'-diarylureas--potential anti-cancer agents. Bioorg Med Chem Lett. 2012;22:402-9.

132. Boyce M, Bryant KF, Jousse C, Long K, Harding HP, Scheuner D, et al. A selective inhibitor of elF2alpha dephosphorylation protects cells from ER stress. Science. 2005;307:935-9.

133. Park G, Bin KYS, Lee H-K, Song H, Kim S, Cho D-H, et al. Reactive oxygen species and p38 MAPK regulate Bax translocation and calcium redistribution in salubrinal-induced apoptosis of EBV-transformed B cells. Cancer Lett. 2011;313:235-48.

134. Tsaytler P, Harding HP, Ron D, Bertolotti A. Selective inhibition of a regulatory subunit of protein phosphatase 1 restores proteostasis. Science. 2011;332:91-4.

135. Hamamura K, Minami K, Tanjung N, Wan Q, Koizumi M, Matsuura N, et al. Attenuation of malignant phenotypes of breast cancer cells through elF2alphamediated downregulation of Rac1 signaling. Int J Oncol. 2014;44:1980-8.

136. Robert F, Kapp LD, Khan SN, Acker MG, Kolitz S, Kazemi S, et al. Initiation of protein synthesis by hepatitis $C$ virus is refractory to reduced elF2.GTP.MettRNA(i)(Met) ternary complex availability. Mol Biol Cell. 2006;17:4632-44.

137. Brady LK, Wang H, Radens CM, Bi Y, Radovich M, Maity A, et al. Transcriptome analysis of hypoxic cancer cells uncovers intron retention in EIF2B5 as a mechanism to inhibit translation. Plos Biol. 2017;15:e2002623.

138. Leegwater PA, Vermeulen G, Könst AA, Naidu S, Mulders J, Visser A, et al. Subunits of the translation initiation factor elF2B are mutant in leukoencephalopathy with vanishing white matter. Nat Genet. 2001;29:383-8.

139. Dietrich J, Lacagnina M, Gass D, Richfield E, Mayer-Pröschel M, Noble M, et al. EIF2B5 mutations compromise GFAP+ astrocyte generation in vanishing white matter leukodystrophy. Nat Med. 2005;11:277-83.

140. Gallagher JW, Kubica N, Kimball SR, Jefferson LS. Reduced eukaryotic initiation factor 2Bepsilon-subunit expression suppresses the transformed phenotype of cells overexpressing the protein. Cancer Res. 2008;68:8752-60.

141. Spilka R, Ernst C, Mehta AK, Haybaeck J. Eukaryotic translation initiation factors in cancer development and progression. Cancer Lett. 2013;340:9-12.

142. Zhang L, Pan X, Hershey JWB. Individual overexpression of five subunits of human translation initiation factor elF3 promotes malignant transformation of immortal fibroblast cells. J Biol Chem. 2007;282:5790-800.

143. Xu T-R, Lu R-F, Romano D, Pitt A, Houslay MD, Milligan G, et al. Eukaryotic translation initiation factor 3 , subunit a, regulates the extracellular signalregulated kinase pathway. Mol Cell Biol. 2012;32:88-95.

144. Rasmussen SB, Kordon E, Callahan R, Smith GH. Evidence for the transforming activity of a truncated Int6 gene, in vitro. Oncogene. 2001;20:5291-301.

145. Grzmil M, Rzymski T, Milani M, Harris AL, Capper RG, Saunders NJ, et al. An oncogenic role of elF3e/INT6 in human breast cancer. Oncogene. 2010;29: 4080-9.

146. Graff JR, Konicek BW, Lynch RL, Dumstorf CA, Dowless MS, McNulty AM, et al. elF4E activation is commonly elevated in advanced human prostate cancers and significantly related to reduced patient survival. Cancer Res. 2009;69:3866-73.

147. Hernandez G, Ramirez JL, Pedroza-Torres A, Herrera LA, Jimenez-Rios MA. The Secret Life of Translation Initiation in Prostate Cancer. Front Genet. 2019;10:14.

148. Alabdullah ML, Ahmad DA, Moseley P, Madhusudan S, Chan S, Rakha E. The mTOR downstream regulator ( $\mathrm{p}-4 \mathrm{EBP} 1$ ) is a novel independent prognostic marker in ovarian cancer. J Obstet Gynaecol. 2019;39:522-8. 
149. Coleman LJ, Peter MB, Teall TJ, Brannan RA, Hanby AM, Honarpisheh H, et al. Combined analysis of elF4E and $4 \mathrm{E}$-binding protein expression predicts breast cancer survival and estimates elF4E activity. Br J Cancer. 2009;100:1393-9.

150. Pyronnet S, Imataka H, Gingras AC, Fukunaga R, Hunter T, Sonenberg N. Human eukaryotic translation initiation factor $4 \mathrm{G}$ (elF4G) recruits Mnk1 to phosphorylate elF4E. EMBO J. 1999;18:270-9.

151. Ueda T, Sasaki M, Elia AJ, Chio IIC, Hamada K, Fukunaga R, et al. Combined deficiency for MAP kinase-interacting kinase 1 and 2 (Mnk1 and Mnk2) delays tumor development. Proc Natl Acad Sci U S A. 2010;107:13984-90.

152. Ueda T, Watanabe-Fukunaga R, Fukuyama H, Nagata S, Fukunaga R. Mnk2 and Mnk1 Are Essential for Constitutive and Inducible Phosphorylation of Eukaryotic Initiation Factor 4E but Not for Cell Growth or Development. Mol Cell Biol. 2004;24:6539-49.

153. Robichaud N, del Rincon SV, Huor B, Alain T, Petruccelli LA, Hearnden J, et al. Phosphorylation of elF4E promotes EMT and metastasis via translational control of SNAIL and MMP-3. Oncogene. 2015;34:2032-42.

154. D'Abronzo LS, Bose S, Crapuchettes ME, Beggs RE, Vinall RL, Tepper CG, et al. The androgen receptor is a negative regulator of elF4E phosphorylation at S209: implications for the use of mTOR inhibitors in advanced prostate cancer. Oncogene. 2017:36:6359-73.

155. D'Abronzo LS, Ghosh PM. elF4E Phosphorylation in Prostate Cancer. Neoplasia. 2018;20:563-73.

156. Grzmil M, Huber RM, Hess D, Frank S, Hynx D, Moncayo G, et al. MNK1 pathway activity maintains protein synthesis in rapalog-treated gliomas. J Clin Invest. 2014;124:742-54.

157. Liu S, Zha J, Lei M. Inhibiting ERK/Mnk/elF4E broadly sensitizes ovarian cancer response to chemotherapy. Clin Transl Oncol. 2018;20:374-81.

158. Pettersson F, Del Rincon SV, Miller WHJ. Eukaryotic translation initiation factor $4 \mathrm{E}$ as a novel therapeutic target in hematological malignancies and beyond. Expert Opin Ther Targets. 2014;18:1035-48.

159. Bordeleau M-E, Mori A, Oberer M, Lindqvist L, Chard LS, Higa T, et al. Functional characterization of IRESes by an inhibitor of the RNA helicase elF4A. Nat Chem Biol. 2006;2:213-20.

160. Bordeleau M-E, Matthews J, Wojnar JM, Lindqvist L, Novac O, Jankowsky E, et al. Stimulation of mammalian translation initiation factor elF4A activity by a small molecule inhibitor of eukaryotic translation. Proc Natl Acad Sci U S A. 2005;102:10460-5.

161. Bordeleau M-E, Robert F, Gerard B, Lindqvist L, Chen SMH, Wendel H-G, et al. Therapeutic suppression of translation initiation modulates chemosensitivity in a mouse lymphoma model. The J Clin Invest. 2008;118: 2651-60.

162. Low W-K, Li J, Zhu M, Kommaraju SS, Shah-Mittal J, Hull K, et al. Secondgeneration derivatives of the eukaryotic translation initiation inhibitor pateamine A targeting elF4A as potential anticancer agents. Bioorg Med Chem. 2014;22:116-25

163. Kuznetsov G, Xu Q, Rudolph-Owen L, Tendyke K, Liu J, Towle M, et al. Potent in vitro and in vivo anticancer activities of des-methyl, des-amino pateamine $\mathrm{A}$, a synthetic analogue of marine natural product pateamine $\mathrm{A}$. Mol Cancer Ther. 2009;8:1250-60.

164. Cencic R, Carrier M, Trnkus A, Porco JAJ, Minden M, Pelletier J. Synergistic effect of inhibiting translation initiation in combination with cytotoxic agents in acute myelogenous leukemia cells. Leuk Res. 2010;34:535-41.

165. Peters TL, Tillotson J, Yeomans AM, Wilmore S, Lemm E, et al. Target-Based Screening against elF4A1 Reveals the Marine Natural Product Elatol as a Novel Inhibitor of Translation Initiation with In Vivo Antitumor Activity. Clin Cancer Res. 2018;24:4256-70.

166. Malina A, Mills JR, Pelletier J. Emerging therapeutics targeting mRNA translation. Cold Spring Harb Perspect Biol. 2012:4:a012377.

167. Wagner CR, lyer W, McIntee EJ. Pronucleotides: toward the in vivo delivery of antiviral and anticancer nucleotides. Med Res Rev. 2000;20:417-51.

168. Assouline S, Culjkovic B, Cocolakis E, Rousseau C, Beslu N, Amri A, et al. Molecular targeting of the oncogene elF4E in acute myeloid leukemia (AML): a proof-of-principle clinical trial with ribavirin. Blood. 2009:114:257-60.

169. Moerke NJ, Aktas H, Chen H, Cantel S, Reibarkh MY, Fahmy A, et al. Smallmolecule inhibition of the interaction between the translation initiation factors elF4E and elF4G. Cell. 2007;128:257-67.

170. Papadopoulos E, Jenni S, Kabha E, Takrouri KJ, Yi T, Salvi N, et al. Structure of the eukaryotic translation initiation factor elF4E in complex with 4EGI-1 reveals an allosteric mechanism for dissociating elF4G. Proc Natl Acad Sci U S A. 2014;111:e3187-95.
171. Duffy AG, Makarova-Rusher OV, Ulahannan SV, Rahma OE, Fioravanti S, Walker $\mathrm{M}$, et al. Modulation of tumor elF4E by antisense inhibition: A phase I/II translational clinical trial of ISIS 183750-an antisense oligonucleotide against elF4E-in combination with irinotecan in solid tumors and irinotecanrefractory colorectal cancer. Int J Cancer. 2016;139:1648-57.

172. Graff JR, Konicek BW, Vincent TM, Lynch RL, Monteith D, Weir SN, et al. Therapeutic suppression of translation initiation factor elF4E expression reduces tumor growth without toxicity. J Clin Invest. 2007;117:2638-48.

173. Lin C-J, Nasr Z, Premsrirut PK, Porco JAJ, Hippo Y, Lowe SW, et al. Targeting synthetic lethal interactions between Myc and the elF4F complex impedes tumorigenesis. Cell Rep. 2012;1:325-33.

174. Balabanov S, Gontarewicz A, Ziegler P, Hartmann U, Kammer W, Copland M, et al. Hypusination of eukaryotic initiation factor 5A (elF5A): a novel therapeutic target in BCR-ABL-positive leukemias identified by a proteomics approach. Blood. 2007;109:1701-11.

175. Gutierrez E, Shin B-S, Woolstenhulme CJ, Kim J-R, Saini P, Buskirk AR, et al. elF5A promotes translation of polyproline motifs. Mol Cell. 2013;51:35-45.

176. Schuller AP, Wu CC-C, Dever TE, Buskirk AR, Green R. elF5A Functions Globally in Translation Elongation and Termination. Mol Cell. 2017:66:194205.e5.

177. Gandin V, Miluzio A, Barbieri AM, Beugnet A, Kiyokawa H, Marchisio PC, et al. Eukaryotic initiation factor 6 is rate-limiting in translation, growth and transformation. Nature. 2008;455:684-8.

178. Brina D, Miluzio A, Ricciardi S, Biffo S. elF6 anti-association activity is required for ribosome biogenesis, translational control and tumor progression. Biochim Biophys Acta. 2015;1849:830-5.

179. Zhu W, Li GX, Chen HL, Liu XY. The role of eukaryotic translation initiation factor 6 in tumors. Oncol Lett. 2017:14:3-9.

180. Miluzio A, Beugnet A, Grosso S, Brina D, Mancino M, Campaner S, et al. Impairment of cytoplasmic elF6 activity restricts lymphomagenesis and tumor progression without affecting normal growth. Cancer Cell. 2011;19: 765-75

181. Furic L, Rong L, Larsson O, Koumakpayi $\|_{\text {, }}$ Yoshida K, Brueschke A, et al. elF4E phosphorylation promotes tumorigenesis and is associated with prostate cancer progression. Proc Natl Acad Sci U S A. 2010;107:14134-9.

\section{Publisher's Note}

Springer Nature remains neutral with regard to jurisdictional claims in published maps and institutional affiliations.

Ready to submit your research? Choose BMC and benefit from:

- fast, convenient online submission

- thorough peer review by experienced researchers in your field

- rapid publication on acceptance

- support for research data, including large and complex data types

- gold Open Access which fosters wider collaboration and increased citations

- maximum visibility for your research: over $100 \mathrm{M}$ website views per year

At $\mathrm{BMC}$, research is always in progress.

Learn more biomedcentral.com/submission 